\title{
Ubiquitin and Ubiquitin-Like Proteins in the Critical Equilibrium between Synapse Physiology and Intellectual Disability
}

\author{
Alessandra Folci, ${ }^{{ }^{*}}$ Filippo Mirabella, ${ }^{2}$ and ${ }^{-}$Matteo Fossati ${ }^{1,3^{*}}$ \\ https://doi.org/10.1523/ENEURO.0137-20.2020 \\ ${ }^{1}$ Humanitas Clinical and Research Center-IRCCS, via Manzoni 56, 20089, Rozzano (MI), Italy, ${ }^{2}$ Department of \\ Biomedical Sciences, Humanitas University, Via Rita Levi Montalcini 4, 20090 Pieve 9 Emanuele - Milan, Italy, and \\ ${ }^{3}$ CNR-Institute of Neuroscience, via Manzoni 56, 20089, Rozzano (MI), Italy
}

\begin{abstract}
Posttranslational modifications (PTMs) represent a dynamic regulatory system that precisely modulates the functional organization of synapses. PTMs consist in target modifications by small chemical moieties or conjugation of lipids, sugars or polypeptides. Among them, ubiquitin and a large family of ubiquitin-like proteins (UBLs) share several features such as the structure of the small protein modifiers, the enzymatic cascades mediating the conjugation process, and the targeted aminoacidic residue. In the brain, ubiquitination and two UBLs, namely sumoylation and the recently discovered neddylation orchestrate fundamental processes including synapse formation, maturation and plasticity, and their alteration is thought to contribute to the development of neurological disorders. Remarkably, emerging evidence suggests that these pathways tightly interplay to modulate the function of several proteins that possess pivotal roles for brain homeostasis as well as failure of this crosstalk seems to be implicated in the development of brain pathologies. In this review, we outline the role of ubiquitination, sumoylation, neddylation, and their functional interplay in synapse physiology and discuss their implication in the molecular pathogenesis of intellectual disability (ID), a neurodevelopmental disorder that is frequently comorbid with a wide spectrum of brain pathologies. Finally, we propose a few outlooks that might contribute to better understand the complexity of these regulatory systems in regard to neuronal circuit pathophysiology.
\end{abstract}

Key words: intellectual disability; ubiquitination; sumoylation; neddylation; synapse development; synapse function

\section{Significance Statement}

Ubiquitination, sumoylation, and neddylation are related PTMs modulating cellular and molecular pathways that are essential to generate fully functional neuronal circuits. Their impairment is indeed implicated in the pathogenesis of several disorders, including ID. Growing evidence now indicates they also functionally cooperate to govern synapse development and function. The main goals of this review are (1) to provide an overview of the current knowledge on the role of ubiquitination, sumoylation, and neddylation in synapse functions; (2) discuss how altered ubiquitination or sumoylation pathways may contribute to ID development; and (3) highlight evidence of a dynamic cross talk between these PTMs, which represents a novel mechanism that could lead to the identification of new principles underlying synaptic function and dysfunction in ID. 


\section{Introduction}

Synapses are the basic functional units of the brain ensuring proper information processing and storage. In the forebrain, glutamate and GABA are the main excitatory and inhibitory neurotransmitters (NTs), respectively. Synaptic transmission occurs when an action potential reaches the active zone of the presynaptic terminal and triggers the $\mathrm{Ca}^{2+}$-dependent fusion of synaptic vesicles (SVs) to the presynaptic membrane (Südhof, 2004). SV fusion releases NT molecules into the synaptic cleft and convey a signal to NT receptors localized in the membrane of a specialized domain of the postsynaptic neuron, called the postsynaptic density (PSD). The PSD is composed by a complex network of distinct protein categories. Among them, postsynaptic NT receptors transduce the signal conveyed by NTs into electrical and biochemical cascades. Underneath the postsynaptic membrane, a meshwork of scaffolding proteins generates a structural platform governing synapse organization via multiple bindings to NT receptors, adhesion proteins, signaling molecules, and cytoskeletal elements (Sheng and Kim, 2011).

A prominent feature of synapses is their ability to dynamically modify the strength of synaptic transmission according to the inputs they receive, in a process called synaptic plasticity. Synaptic plasticity is thought to underlie learning and memory and is fundamental to adapt our behavior based on experience. During brain development, synaptic plasticity peaks in specific temporal windows of high sensitivity, called critical periods (Hensch, 2005), which are crucial to orchestrate the formation and refinement of synaptic networks and, ultimately, enables the acquisition of a given skill and/or cognitive function. The drawback of this particularly high sensitivity is a marked susceptibility to genetic and environmental insults that can interfere with molecular and cellular processes critical to synapse development, function, and plasticity. Indeed, perturbation of these pathways leads to neurodevelopmental and psychiatric disorders, such as autism, ID, and schizophrenia. Since these pathologies are characterized by the convergence of distinct pathways onto synaptic impairment, they are collectively defined as synaptopathies (Van Spronsen and Hoogenraad, 2010). To date, no effective therapies are available to treat these diseases. It is therefore crucial to understand the molecular mechanisms of synaptic dysfunction to

This work was supported by the Italian Ministry of Health (GR-201812366478 to M.F.) and the European Union's Horizon 2020 research and innovation programme (Marie Sklodowska-Curie grant agreement 845466 to A.F.).

${ }^{*}$ A.F. and M.F. contributed equally to this work.

Acknowledgements: We thank Michela Matteoli (IN-CNR and Hunimed, Rozzano, Italy), Davide Pozzi (Hunimed, Rozzano, Italy), and Marta Prieto (IPMC, Valbonne, France) for critically reading of this manuscript.

Correspondence should be addressed to Alessandra Folci at alessandra. folci@humanitasresearch.it or Matteo Fossati at matteo.fossati@in.cnr.it.

https://doi.org/10.1523/ENEURO.0137-20.2020 Copyright (C) 2020 Folci et al.

This is an open-access article distributed under the terms of the Creative Commons Attribution 4.0 International license, which permits unrestricted use, distribution and reproduction in any medium provided that the original work is properly attributed. provide the rationale to develop innovative therapeutic approaches.

Given the plastic nature of the brain, synapses have developed strategies to rapidly modify the strength of synaptic transmission. The dynamic modulation of protein activity via PTMs is a major mechanism to efficiently tune synapse assembly, maturation, and function. PTMs refer to covalent enzymatic modifications, either reversible or irreversible of target proteins, following their translation (Bürkle, 2001). They typically consist in the addition of a functional moiety, which can be either chemical groups or complex molecules, including lipids, sugars, nucleosides, and polypeptides to specific residues of target proteins. PTMs regulate multiple aspects of protein physiology from subcellular localization and activity to conformation and stability/turnover. In neurons, PTMs have been extensively investigated and modulate virtually all pathways that are required to ensure proper synaptic transmission and plasticity, such as presynaptic NT release (Takahashi et al., 2003; Hegde and DiAntonio, 2002; Schorova and Martin, 2016), trafficking and biophysical properties of NT receptors (Luscher et al., 2011; Schorova and Martin, 2016; Diering and Huganir, 2018), PSD organization (Zacchi et al., 2014; Coba, 2019), and synaptic adhesion (Jeong et al., 2017). Beyond the essential roles of PTMs in brain physiology, their impairment is thought to critically contribute to the etiology of several brain disorders including synaptopathies. Among PTMs, ubiquitination and ubiquitin-like proteins (UBLs) such as sumoylation and neddylation share multiple features, tightly interplay, and are vital to synapse assembly, maturation, and function. In this review, we focus on the role of ubiquitination, sumoylation, and neddylation in synapse physiology and their implication in the molecular pathogenesis of ID, a generalized neurodevelopmental disorder that manifests in a wide range of brain pathologies (Verpelli and Sala, 2012; Picker and Walsh, 2013; Vissers et al., 2016).

\section{Ubiquitination and UBL Pathways in Synapse Physiology}

\section{Ubiquitination}

Ubiquitination occurs in all eukaryotic cells. It consists in the reversible conjugation of the 76 amino acid (aa)long ubiquitin protein to lysine $(\mathrm{K})$ residues of target proteins. This process is catalyzed by a series of enzymatic reactions. E1 ubiquitin enzymes bind to and activate free ubiquitin through adenylation at ubiquitin C-terminal and thiol transfer. Activated ubiquitin is then transferred to E2 ubiquitin-conjugating enzymes and finally transferred onto a $\mathrm{K}$ residue of target proteins by E3 ubiquitin ligases. Protein substrates can be either mono-ubiquitinated or poly-ubiquitinated and ubiquitin chains can vary depending on which of the seven $\mathrm{K}$ residues of ubiquitin is used to covalently attach the subsequent ubiquitin (for a comprehensive review, see Komander and Rape, 2012). The human genome encodes two E1, $50 \mathrm{E} 2$, and $\sim 600 \mathrm{E} 3$ enzymes. Thus, substrate specificity mainly relies on E3 ligases and different combinations of E2-E3 proteins. Ubiquitination is counterbalanced by the action of 
deubiquitinating enzymes (DUBs) that remove ubiquitin from target proteins. The coordinated activity of ubiquitinating enzymes and DUBs is essential to set and maintain ubiquitin homeostasis (Kowalski and Juo, 2012).

Protein degradation through the ubiquitin proteasome system (UPS) is the best characterized function of ubiquitination and K48 poly-ubiquitin chains are the most common signal to target proteins for degradation. Conversely, mono-ubiquitination and K63 poly-ubiquitin chains mediate non-proteasomal functions and typically modulate phosphorylation-dependent protein activation, protein-protein interactions, and membrane protein trafficking (Komander and Rape, 2012). Both proteasomal and non-proteasomal ubiquitin conjugations occur at the synapse, where they regulate molecular processes important for synapse formation, maturation, and plasticity. As a consequence, ubiquitination is critical for long-term memory formation and stability as observed with a variety of behavioral paradigms (for review, see Jarome and Helmstetter, 2013).

\section{Presynaptic ubiquitination}

The importance of ubiquitination to the presynaptic function was first described in Drosophila neuromuscular junctions (NMJs). Pharmacological and genetic perturbations of the UPS lead to the accumulation of Dunc-13, a protein important for SV release, and significantly increase presynaptic efficacy (Speese et al., 2003). In line with this, MUN-13, the mouse ortholog of Dunc-13 is also ubiquitinated by the E3 ligase FBXO45 in the hippocampus (Tada et al., 2010; Fig. 1A). Syntaxin 1 (STX1), a major component of the SNAP REceptor (SNARE) complex and the binding partner of the presynaptic $\mathrm{Ca}^{2+}$ sensor synaptotagmin (Rizo and Xu, 2015), is poly-ubiquitinated by the E3 enzyme Staring (Chin et al., 2002; Fig. 1A). Ubiquitination further regulates NT release by targeting the presynaptically expressed Group III metabotropic glutamate (mGlu)7 receptor, which inhibits glutamate and GABA release (Niswender and Conn, 2010). Upon stimulation with L-glutamate, the E3 ligase NEDD4 induces rapid mGlu7 internalization and degradation via both proteasomal and lysosomal pathways (Lee et al., 2019; Fig. 1A). Protein degradation via the UPS is also a major regulator of SV recycling (Willeumier et al., 2006). Interestingly, blocking action potentials with tetrodotoxin (TXX) prevents the effect of proteasome inhibition on the recycling vesicle pool, suggesting that presynaptic UPS may be a negative feedback-regulator of synaptic transmission.

Beside basal synaptic transmission, presynaptic ubiquitination is also a critical determinant of synaptic plasticity and is required for cognition. Genetic deletion of the gene enconding the anaphase-promoting complex/cyclosome (APC/C) in the forebrain of adult mice impairs hippocampal-dependent memories, such as spatial memory and extinction of fear memory resulting in anxiety-related behaviors (Li et al., 2008; Kuczera et al., 2010). While at Drosophila and Caenorhabditis elegans NMJs it is known that APC/C targets the active zone protein Liprin- $\alpha$ (van Roessel et al., 2004; Kowalski et al., 2014), the presynaptic targets in mammals remain elusive. Recently, the E3 ligase RNF8 was shown to be required to build up cerebellar circuits mediating procedural motor learning by limiting the formation of parallel fiber presynaptic boutons onto Purkinje cells by targeting as yet unidentified substrates (Valnegri et al., 2017). Another presynaptic E3 ligase fundamental to establish neuronal connectivity is SCRAPPER. In mouse hippocampal neurons, SCRAPPER modulates multiple aspects of the presynaptic function by directly ubiquitinating and regulating Rab3-interacting protein 1 (RIM1; Fig. 1A). Consistent with the role of RIM1 as major SV priming factor (Südhof, 2004), axonal boutons of Scrapper-knock-out (KO) neurons show enhanced synaptic transmission, owing a significant increase of NT release probability (Yao et al., 2007; Takagi et al., 2012). Moreover, the absence of Scrapper expression interferes with performances in contextual fear conditioning tests and hippocampi derived from these mice exhibit bidirectional changes of synaptic plasticity regulation (also referred to as metaplasticity; Yao et al., 2011; Takagi et al., 2012). These cellular and behavioral features partially recapitulate defects observed in Rim1-KO animals (Castillo et al., 2002; Powell et al., 2004), although there may be other SCRAPPER synaptic targets. Finally, a spontaneous mutation in the Usp14 gene, encoding the proteasomeassociated deubiquitinating enzyme USP14 (Fig. 1A), leads to progressive locomotor defects and ataxia (Wilson et al., 2002). Loss of Usp14 results in impaired short-term facilitation and reduced SV number, indicating the importance of a balanced ubiquitination to preserve presynaptic functions (Walters et al., 2014). However, which proteins are targeted by USP14 and whether USP14 facilitates or inhibits presynaptic UPS are still unclear.

Intriguingly, two large scaffolding proteins of the active zone, Piccolo and Bassoon, were suggested to be important regulators of presynaptic ubiquitination (Waites et al., 2013). Interference with the expression of these genes leads to aberrant degradation of proteins operating in the active zone and degeneration of presynaptic boutons. As this phenotype is partially rescued by either the inhibition of the proteasome or the downregulation of the E3 ligase $\mathrm{SIAH} 1$, it is likely that Piccolo and Bassoon limit presynaptic ubiquitination via the suppression of SIAH1 activity.

Altogether, the aforementioned studies clearly indicate that ubiquitination is critical to NT release, the primary function of presynaptic terminals, and at the circuit level participates to memory and learning processes.

\section{Postsynaptic ubiquitination}

At the postsynaptic site, ubiquitination is a key mechanism that shapes the functional organization of both excitatory and inhibitory synapses by targeting multiple categories of postsynaptic proteins (Fig. $1 A, C$ ). Consistent with this, the proteasome is rapidly recruited and trapped into dendritic spines, the major site for excitatory synapses, after membrane depolarization (Bingol and Schuman, 2006; Bingol et al., 2010).

One of the most well-studied ubiquitinated NT receptors are AMPA receptors (AMPARs; Figs. 1A, 2). They are glutamate-gated ion channels (also referred to as ionotropic glutamate receptors, iGluRs) and mediate the fast excitatory transmission in the brain (Greger et al., 2017). The regulation of their number at the synaptic surface is a 


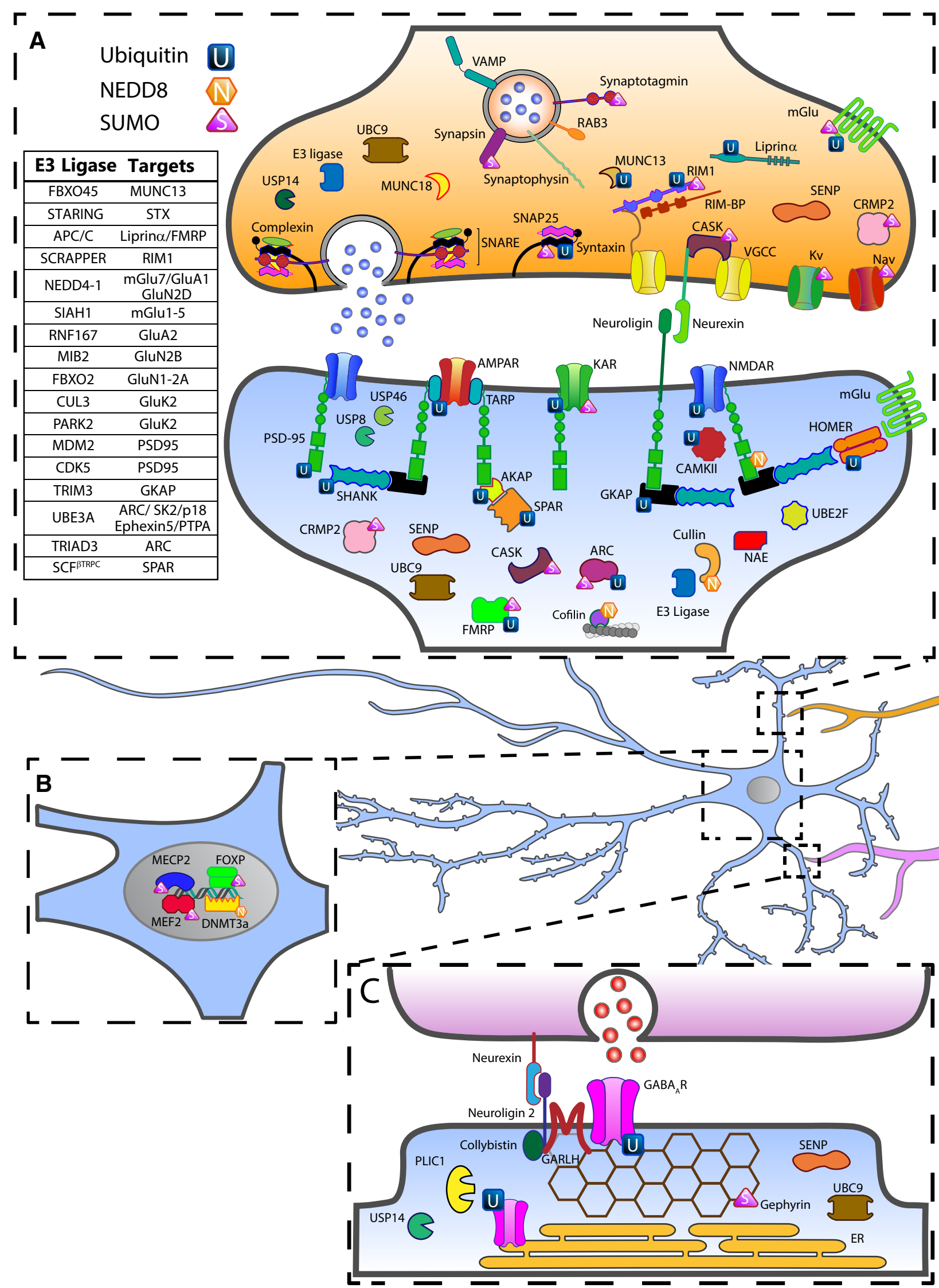

Figure 1. Neuronal ubiquitination and ubiquitin-like modifications. $\boldsymbol{A}, \boldsymbol{C}$, Major components of excitatory and inhibitory synapses 
continued

targeted by ubiquitin (blue squares) SUMO (purple triangles) and NEDD8 (orange hexagons) pathways. Deubiquitinating enzymes (green clamshell-like shapes) and components of the SUMO (UBC9 and SENPS) and NEDD8 machineries (NAE, UBC12, and UBE2F) are also indicated. Although NEDD8 pathway and targets are also present in the presynaptic compartment, for simplicity they are depicted in the postsynaptic region only. In $\boldsymbol{A}$, E3 ubiquitin ligases operating at excitatory synapses and their known substrates are listed in the left table. $\boldsymbol{B}$, Nuclear sumoylation and neddylation critical to synaptic function are indicated.

major determinant of synaptic strength and plasticity (Choquet and Triller, 2013; Huganir and Nicoll, 2013). The importance of AMPAR ubiquitination was first demonstrated in C. elegans, where it controls synaptic abundance of these receptors and locomotor behavior (Burbea et al., 2002; Juo and Kaplan, 2004; Dreier et al., 2005; Emtage et al., 2009). In mammals, the selective ubiquitination of GluA1 and GluA2 subunits is required for the activity-dependent endocytosis of surface AMPARs directing them toward degradative pathways. Ubiquitination occurs at $\mathrm{K}$ residues of their intracellular $\mathrm{C}$-terminal tail via the $\mathrm{E} 3$ ligases NEDD4-1 and RNF167 (Schwarz et al., 2010; Lussier et al., 2011, 2012). A more recent study showed that activity-dependent AMPAR ubiquitination involves all four GluA subunits (GluA1-4) and sorts AMPARs from early to late endosomes and subsequent lysosome-dependent degradation (Widagdo et al., 2015). Considering that the modulation of AMPAR number at synaptic sites tunes synaptic strength and plasticity, it is expected that AMPAR ubiquitination has implication in learning and memory paradigms. Consistently, proteasome inhibition increases synaptic surface GluA1-containing AMPARs and enhances fear-conditioned learning (Yeh et al., 2006). UPS-dependent degradation of GluA1 also facilitates the extinction of fear memories, which is mediated by NMDAR-dependent depression of synaptic activity (Mao et al., 2008). AMPAR ubiquitination is finely counteracted by the opposite action of a few DUBs. Overexpression of Usp46 prolongs GluA1 half-life, resulting in enhanced amplitude of excitatory postsynaptic currents (Huo et al., 2015). USP8 antagonizes the E3 ligase NEDD4-1 and is involved in downscaling synaptic strength during homeostatic plasticity, providing the first evidence for an opposed bidirectional control of synaptic strength by ubiquitination (Scudder et al., 2014).

Among the iGluR family, NMDA receptors (NMDARs) play an essential role in synaptic plasticity (Paoletti et al., 2013), and their function, similarly to other iGluR members, is modulated by ubiquitination (Figs. $1 A, 2$ ). The GluN2B, GluN2D, GluN1, and GluN2A subunits are targeted by the E3 ubiquitin ligases Mind bomb-2 (MIB2), NEDD4, and FBXO2 (Kato et al., 2005; Jurd et al., 2008; Gautam et al., 2013; Atkin et al., 2015). Upon phosphorylation-dependent ubiquitination of GluN2B by MIB2 in the PSD, NMDAR-mediated currents are significantly reduced. This effect is prevented when cells are treated with the proteasome inhibitor MG132, suggesting that ubiquitinated GluN2B undergoes UPS-dependent degradation (Jurd et al., 2008). Similarly, NEDD4 selectively conjugates poly-ubiquitin chains to GluN2D and reduces NMDAR currents in heterologous cells (Gautam et al., 2013). Whether ubiquitination directly mediates GluN2D proteasome-dependent degradation or modulates receptor endocytosis and sorting to late endosomes and lysosomes is not known. Conversely, FBXO2 ubiquitinates newly synthetized GluN1 and GluN2A subunits in the endoplasmic reticulum (ER) and mediates its degradation via the ER-associated degradation (ERAD) machinery, a mechanism that avoids the formation of supranumerary synapses in the dendritic shaft and aberrant NMDAR-mediated currents (Kato et al., 2005; Nelson et al., 2006; Gascón et al., 2007; Atkin et al., 2015). Synaptic abundance and clustering of GluN1-containing NMDARs are also modulated by the hominoid-specific DUB USP6 (Zeng et al., 2019). By generating a humanized knock-in (KI) mouse expressing USP6 under the control of $\mathrm{Ca}^{2+}$ / calmodulin-dependent kinase II (CamkIl) promoter, the authors found that USP6 stabilizes NMDARs at synapses and enhances synaptic function resulting in improved mouse cognitive abilities. Beside the novel synaptic mechanism uncovered here, this study suggests for the first time that ubiquitination may have contributed to the evolution of human-specific synaptic features, which are thought to form, together with other processes the cellular basis of human intelligence (DeFelipe, 2011; Geschwind and Rakic, 2013). In line with this, perturbation of USP6 is associated with human-specific neuropsychiatric disorders, such as ID (Ou et al., 2006) and autism spectrum disorders (ASD; Tentler et al., 2003).

Kainate receptors (KARs) are the third receptor subtypes of iGluRs whose activity and trafficking are modulated by ubiquitination (Figs. 1A, 2). The E3 ligases Cullin 3 (CUL3) and Parkin 2 (PARK2) target the GluK2 subunit of KARs and regulate its surface expression (Salinas et al., 2006; Maraschi et al., 2014). Strikingly, loss-of-function of PARK2, which is causative of the most common form of familial juvenile parkinsonism, leads to abnormal levels of synaptic GluK2, a mechanism that could underlie glutamate excitotoxicity and neurodegeneration in Parkinson's disease. Yet, it is unclear whether KAR ubiquitination occurs on surface receptors and whether it is degraded through UPS or lysosomal pathway.

mGlu receptors are also targeted by ubiquitination at the postsynaptic compartment (Figs. 1A, 2). Upon dihydroxyphenylglycine (DHPG)-induced activation of Group I mGlu1-5, the E3 ligase SIAH1 attaches K63linked poly-ubiquitin chains to intracellular $\mathrm{K}$ residues of these receptors and induces their internalization (Moriyoshi et al., 2004; Ko et al., 2012; Gulia et al., 2017). Since their activation is critical for the expression of long-term depression (LTD; Niswender and Conn, 2010), mGlu receptor ubiquitination emerged as an essential regulatory mechanism limiting excessive synaptic depression (Gulia et al., 2017).

As aforementioned, postsynaptic scaffolding proteins are the structural core of the PSD. Here, complex proteinprotein interactions are tightly regulated by PTMs to 


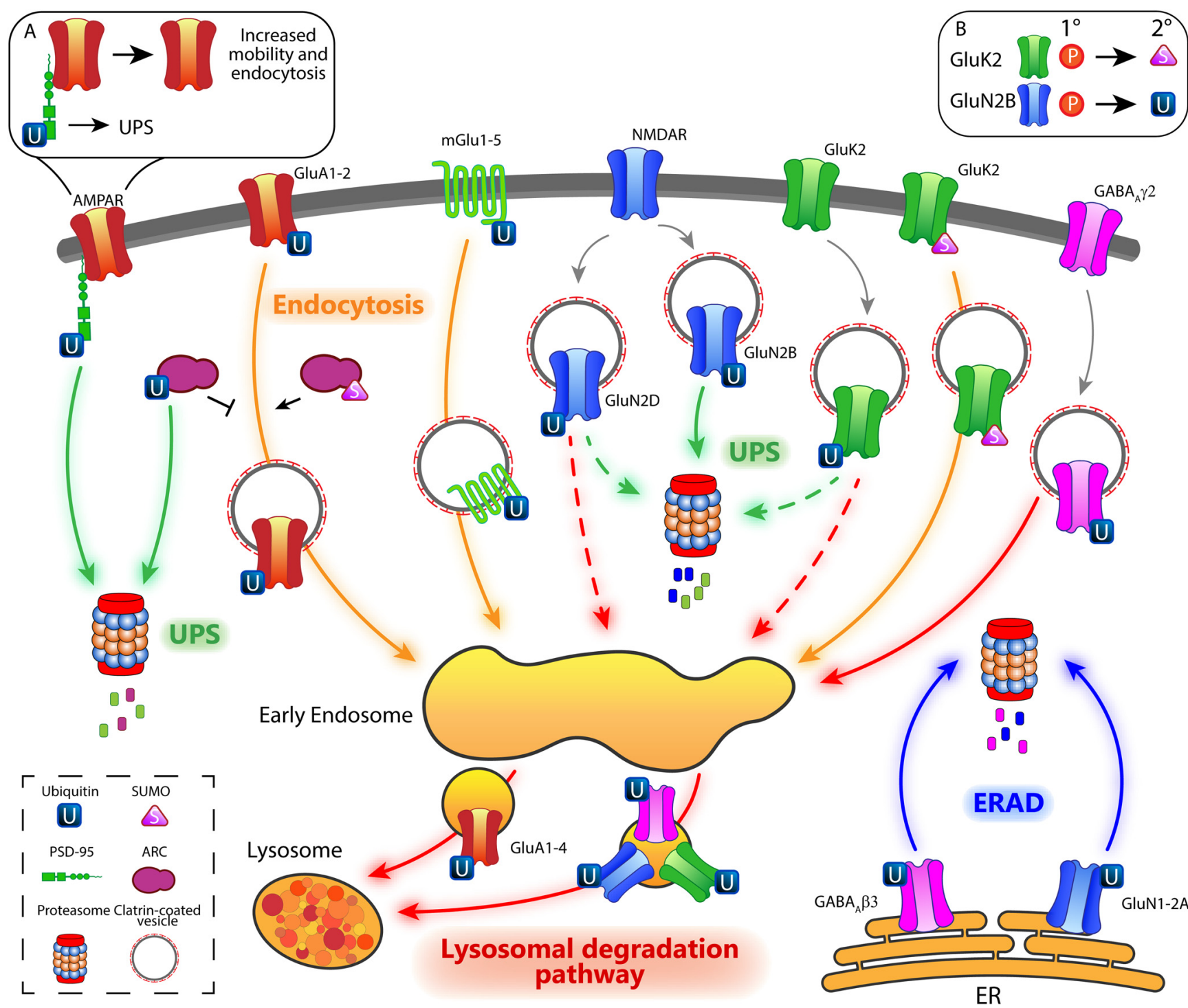

Figure 2. Postsynaptic control of glutamate and $\mathrm{GABA}_{\mathrm{A}}$ receptors by ubiquitination and sumoylation. UPS-dependent degradation (green arrows) of PSD-95 destabilizes surface AMPARs, resulting in enhanced receptor lateral mobility and consequently, endocytosis (box A). Ubiquitination of GluA1 and GluA2 decreases surface AMPARs through clathrin-dependent endocytosis (orange arrows). Ubiquitinated ARC is degraded via the UPS pathway. As ARC is a major regulator of AMPAR internalization, reduced ARC levels suppress AMPAR endocytosis. Conversely, sumoylated ARC triggers AMPAR internalization. Moreover, ubiquitination of intracellular GluA1-4 may also promote AMPAR sorting to the lysosomal degradation pathway (red arrows). Ubiquitination of mGlu1-5 receptors enhanced their clathrin-dependent endocytosis. Surface NMDARs are regulated by the ubiquitination pathway in a subunitdependent manner. GluN2B undergoes a phosphorylation-dependent ubiquitination (box $\boldsymbol{B}$ ), leading to UPS-dependent degradation of NMDARs. GluN2D ubiquitination enhances its degradation, although it is not clear whether it utilizes UPS-dependent or lysosomal-dependent pathways (green and red dotted arrows). Finally, ubiquitination of newly synthetized GluN1 and GluN2A results in NMDAR retrotranslocation from the ER to the cytosol and subsequent degradation through the ERAD pathway (blue arrows). Similar to GluN2D, GluK2 ubiquitination is phosphorylation-dependent and triggers its degradation through an as yet ill-defined pathway (green and red dotted arrows). In contrast, sumoylated GluK2-containing KARs are removed from the synaptic membrane via clathrin-dependent endocytosis. At inhibitory synapses, ubiquitinated $\gamma 2$-containing $\mathrm{GABA}_{\mathrm{A}} \mathrm{R}$ are sorted to the lysosomal degradation pathway, while $\beta 3$-containing $\mathrm{GABA}_{\mathrm{A}} \mathrm{R}$ are ubiquitinated in the ER and degraded through the ERAD machinery.

control the functional organization of synapses (Sheng and Hoogenraad, 2007). Given the multiple protein-protein interactions that each scaffolding protein engages, the ubiquitination of a few scaffolding proteins allows the precise regulation of a large set of postsynaptic molecules (Fig. 1A). PSD-95, GKAP, AKAP79/150, SHANK, and HOMER1A are abundant scaffolding proteins of excitatory synapses and their levels are bidirectionally modulated by ubiquitination in an activity-dependent manner (Ageta et al., 2001; Colledge et al., 2003; Ehlers, 2003; Rezvani et al., 2007; Na et al., 2012). Importantly, the targeted degradation of scaffolding molecules critically contributes to learning and behavior. Retrieval of fear memory upregulates polyubiquitinated SHANK and 
GKAP, but not PSD-95. Consistent with this, infusion of the proteasome inhibitor clasto-lactacystin- $\beta$-lactone in the CA1 region of the hippocampus immediately after retrieval prevents extinction of fear memory (Lee et al., 2008). To date, only few of the E3 ligases targeting scaffolding proteins were identified. The E3 ligase MDM2 ubiquitinates PSD-95 at multiple residues and induces distinct pathways. The mono-ubiquitination of PSD-95 within the PEST (peptides rich in proline, glutamate, serine, and threonine) motif, a short sequence serving as proteolytic signal, triggers PSD-95 degradation. As a consequence, the number of PSD-95 molecules available to anchor AMPARs is reduced, resulting in less stable surface AMPARs and enhanced endocytosis (Fig. 2), a mechanism that critically contributes to hippocampal LTD (Colledge et al., 2003). Conversely, the CDK5-dependent ubiquitination of PSD-95 at K10 promotes its interaction with and the recruitment of the clathrin adaptor protein complex (AP)2 at the synapse, triggering clathrindependent AMPAR endocytosis (Bianchetta et al., 2011). The ubiquitination of GKAP, mediated by the E3 ubiquitin ligase TRIM3, induces structural changes of dendritic spines (Hung et al., 2010). While the enzymes mediating SHANK ubiquitination are not known, it has been recently found that USP8 selectively deubiquitinates SHANK1 and SHANK3 and modulates dendritic spine density and morphology (Campbell and Sheng, 2018).

Among postsynaptic signaling proteins, the ubiquitination of the immediate early gene activity-regulated cytoskeleton-associated protein ARC is best characterized (Figs. 1A, 2). ARC responds to various forms of synaptic plasticity and promotes the endocytosis of AMPARs (Shepherd et al., 2006; Waung et al., 2008). UBE3A is the main causal gene of a severe neurodevelopmental disorder, the Angelman syndrome (AS), and encodes the first E3 ligase proposed to target ARC (Greer et al., 2010). Since UBE3A is also a transcriptional coregulator (Nawaz et al., 1999), it is unclear whether UBE3A-dependent regulation of $A R C$ operates at the protein level through ubiquitination or at the transcriptional level (Kühnle et al., 2013). Other studies indicated that $A R C$ is ubiquitinated by the E3 ligase TRIAD3 (Na et al., 2012; Mabb et al., 2014). Another signaling protein targeted by ubiquitination is the spine-associated Rap GTPase activating protein (SPAR; Fig. 1A). SPAR forms a complex with PSD-95 and NMDARs and is critical for spine structural plasticity (Pak et al., 2001). Upon induction of synaptic down-scaling, phosphorylated SPAR is ubiquitinated by the $\mathrm{E} 3$ ligase complex $\mathrm{SCF}^{\beta} \mathrm{TRPC}^{\mathrm{SPA}}$ resulting in its degradation and spine morphology changes (Pak and Sheng, 2003; Ang et al., 2008). Eventually, proteomic approaches aimed at identifying synaptic ubiquitome in rat brains revealed that the CAMKII, which is crucial for the expression of synaptic plasticity (Coultrap and Bayer, 2012), is ubiquitinated ( $\mathrm{Na}$ et al., 2012; Fig. 1A). Yet, the identity of the E3 ligase that targets CAMKII, the consequences on CAMKII stability and the functional relevance for plasticity remain to be assessed.

Ubiquitination was also studied at inhibitory synapses (Fig. 1C). The number of surface $\mathrm{GABA}_{A} \mathrm{Rs}$ is critically modulated by the ubiquitin-associated chaperon PLIC-1 (also named ubiquilin; Bedford et al., 2001; Zhang et al., 2015). Given the association of PLIC proteins with the proteasome in the ER (Kleijnen et al., 2000), it was proposed that PLIC-1 inhibits GABA $_{A} R$ degradation via ERAD (Bedford et al., 2001; Saliba et al., 2008). Accordingly, synaptic upregulation and downregulation of surface $\mathrm{GABA}_{A}$ Rs are governed by changes in poly-ubiquitination dynamics of newly synthesized $\beta 3$ subunits in the ER (Saliba et al., 2007; Fig. 2). In contrast, the ubiquitination of the $\gamma 2$ subunit does not alter the forward-directed biosynthetic route, but instead triggers $G A B A_{A} R$ endocytosis and subsequent lysosome-dependent degradation (Arancibia-Cárcamo et al., 2009; Jin et al., 2014; Fig. 2). In the cerebellum, the USP14-dependent deubiquitination of the $\alpha 1$ subunit, which is contained in the majority of cerebellar $\mathrm{GABA}_{A} \mathrm{Rs}$, reduces surface $\mathrm{GABA}_{A} \mathrm{Rs}$ and favors receptor sorting toward lysosomal compartments (Lappe-Siefke et al., 2009; Fig. 1C). At inhibitory synapses, unlike their glutamatergic counterparts, no scaffolding proteins were found ubiquitinated, so far. Notwithstanding, gephyrin, the major scaffolding protein of inhibitory synapses (Tyagarajan and Fritschy, 2014), contains two PEST sequences (Tyagarajan et al., 2011). Whether these PEST motifs, as that of PSD-95, are targeted by ubiquitination is unclear.

Collectively, there is strong evidence that ubiquitination targets multiple synaptic components and represents a complex regulatory system controlling synapse formation, maintenance, and plasticity. In line with this, ubiquitination is also required for learning and memory. However, the molecular logic of how the ubiquitin system controls cognition and how targeted ubiquitination determines specific behavioral outputs remain enigmatic.

\section{Sumoylation}

Sumoylation consists in the covalent but reversible conjugation of the 100-aa-long small ubiquitin-like modifier (SUMO) protein to specific K residues of substrates (for a more comprehensive review, see Flotho and Melchior, 2013). Like ubiquitination, sumoylation requires a dedicated enzymatic pathway and its homeostasis is finely regulated by conjugating and deconjugating enzymes. SUMO is first synthetized as a non-conjugatable precursor that is cleaved by Sentrin-proteases (SENPS) to generate a mature SUMO molecule. Mature SUMO is subsequently activated by heterodimers of SUMO-activating enzyme (SAE)1 and SAE2 in an ATP-dependent manner and transferred to the catalytic cysteine of the sole SUMO-specific conjugating enzyme UBC9. UBC9 finally catalyzes SUMO conjugation to designated substrates. Targeted $\mathrm{K}$ residues typically localize within the consensus motif $\Psi-\mathrm{K}-\mathrm{x}-\mathrm{E}$, where $\Psi$ is a hydrophobic residue and $x$ is any aa. SUMO deconjugation occurs through the activity of SENPs. Mammalian cells express three different SUMO paralogues (SUMO1-3) and six SENPs (SENP1-3, SENP5-7). As all PTMs, sumoylation modulates the function of target proteins by distinct mechanisms. It can (1) trigger conformational changes that affect protein activity; (2) inhibit or favor protein-protein interactions by either generating or masking a binding site; 
(3) control substrate stability and turnover through a SUMO-mediated recruitment of members of the SUMOtargeted ubiquitin ligase family (Flotho and Melchior, 2013).

Originally, sumoylation was described as nuclear modification regulating protein translocation across the nuclear membrane and transcription (Matunis et al., 1996; Mahajan et al., 1997). Since then, many other SUMO substrates were identified inside and outside the nuclear compartment, including synapses. It is now well accepted that sumoylation controls several processes critical for neuronal function such as neuronal excitability and synapse development and plasticity (Schorova and Martin, 2016; Henley et al., 2018). During brain development, the SUMO machinery and neuronal sumoylome dynamics are tightly regulated in a spatiotemporal manner. In the brain, the overall expression of SUMO components and SUMOconjugated proteins peaks during late stages of embryonic development (embryonic day (E)13-E18) and rapidly decreases postnatally (Watanabe et al., 2008; Loriol et al., 2012; Hasegawa et al., 2014; Josa-Prado et al., 2019). In addition, these proteins are redistributed from the nucleus to the synapse after birth (Loriol et al., 2012), where sumoylation still occurs in mature cortical/hippocampal neurons and is rapidly enhanced by neuronal activity (Loriol et al., 2013; Colnaghi et al., 2019). According to the critical role of sumoylation in controlling synaptic function, UBC9 and SENP1 enzymes dynamically diffuse inside and outside dendritic spines in an activity-dependent manner (Loriol et al., 2014; Schorova et al., 2019). The activation of mGlu5 triggers the transient trapping of UBC9 in the head of dendritic spines, leading to a rapid increase in synaptic sumoylation (Loriol et al., 2014). UBC9 recruitment is followed by time-dependent decrease in the exit rate of SENP1 from dendritic spines, resulting in the postsynaptic accumulation of SENP1, which restores synaptic sumoylation to initial levels (Schorova et al., 2019). Moreover, perturbation of SUMO homeostasis affects synapse physiology and consequently impacts cognitive functions. Decreasing sumoylation levels by overexpressing either a dominant negative form of UBC9 or the catalytic domain of SENP1 prevents the increase of surface AMPARs upon long-term potentiation (LTP) induction, indicating that sumoylation is essential for the expression of synaptic plasticity (Jaafari et al., 2013). Accordingly, acute inhibition of sumoylation impairs hippocampal-dependent learning and memory in mice (Lee et al., 2014). Neuron-specific silencing of SUMO1-3 induces anxiety-like responses and impaired episodic memory providing the first evidence that SUMO conjugation is essential for emotionality and cognition (Wang et al., 2014). Conversely, increase of global SUMO1-ylation in SUMO1 transgenic mice or by chronic infusion of exogenous SUMO1 impairs learning and memory performances (Matsuzaki et al., 2015; Yoo et al., 2017). Furthermore, the loss of SENP2 in conditional KO mice results in several behavioral defects including spatial working memory impairment (Huang et al., 2020). RNA sequencing also revealed that the expression of genes critical for learning and memory is finely regulated by SENP2.

Together, these findings pointed out that sumoylation is essential to synapse development and function, and a balanced sumoylation/desumoylation is crucial for learning and memory processes. In line with this, over the last decade, several groups identified novel SUMO targets critical to synaptic function (Schorova and Martin, 2016; Henley et al., 2018).

\section{Extrasynaptic sumoylation critical to the synaptic function}

The first identified SUMO substrates bearing synaptic functions were components of the myocyte enhancer factor 2 (MEF2) family of transcription factors (Fig. 1B). In vitro and in vivo studies showed that sumoylation represses the transcriptional activity of MEF2A, MEF2C, and MEF2D (Grégoire et al., 2006; Kang et al., 2006; Shalizi et al., 2006). In particular, MEF2A sumoylation at K403 is critical for dendritic claw differentiation in the cerebellum via transcriptional inhibition of the transcription factor Nur77 (Shalizi et al., 2006). Interestingly, MEF2A sumoylation is tightly modulated by neuronal activity and requires a complex cross talk with other PTMs. The $\mathrm{Ca}^{2+}$ dependent phosphatase calcineurin dephosphorylates MEF2A at serine (S)408 and triggers the switch of K403 from being sumoylated to acetylated, resulting in the activation of MEF2A. Acetylated MEF2A thus enhances Nur77 transcription and leads to the inhibition of dendritic claw formation. Subsequently, it was also demonstrated that MEF2A sumoylation is critical for presynaptic differentiation by regulating the transcription of synaptotagmin 1 , thus indicating that MEF2A sumoylation has a broader role in synaptic development (Shalizi et al., 2007).

A second extrasynaptic target of the SUMO machinery is the DNA binding protein and transcriptional repressor Methyl-CpG binding protein 2 (MECP2; Fig. 1B). Sumoylation at K223 of MECP2 is required for the recruitment of histone deacetylase complexes 1/2 (HDAC 1/2) and the consequent repression of gene expression, an essential event for the correct development of hippocampal excitatory synapses in vitro and in vivo (Cheng et al., 2014). Conversely, sumoylation at K412 decreases the physical interaction between MECP2 and the CAMP response element-binding protein (CREB), which ultimately enhances the transcription of the brain-derived neurotrophic factor (Bdnf) transcription (Tai et al., 2016). Similar to MEF2A, MECP2 phosphorylation in nearby residues (S421 and threonine 'T'308) facilitates MECP2 sumoylation, further highlighting the functional interplay between distinct PTMs. As described below, mutations in MECP2 gene are associated with neurodevelopmental disorders, among which the Rett syndrome (RTT) is the most prevalent (Guy et al., 2011).

Recently, two other transcription factors, FOXP1 and FOXP2, were found sumoylated (Fig. 1B). These factors are required for the assembly of cerebellar circuits underlying vocalization and motor skills (Bacon and Rappold, 2012). FOXP2 sumoylation at K674 regulates its transcriptional activity (Estruch et al., 2016; Meredith et al., 2016) and mediates dendritic outgrowth and arborization of Purkinje cells (Usui et al., 2017). In line with this, individuals from a family affected by speech and language disorders display a significant reduction of sumoylated FOXP2, supporting the pivotal role of FOXP2 sumoylation for the acquisition of these communication skills (Meredith et al., 
2016). Similarly to FOXP2, FOXP1 sumoylation at K670 is indispensable for dendritic outgrowth and complexity in cortical neurons via inhibition of FOXP1 transcriptional activity (Rocca et al., 2017). Remarkably, the autism-linked CNTNAP2 gene, which promotes the development of dendritic arbors, is transcriptionally repressed by sumoylated FOXP1, suggesting a potential molecular mechanism underlying FOXP1 function during neuronal development (Rocca et al., 2017).

Fragile $\mathrm{X}$ mental retardation protein (FMRP) is the most recently identified extrasynaptic SUMO target with synaptic roles (Khayachi et al., 2018; Fig. 1B). FMRP is an RNAbinding protein and a key component of neuronal mRNA granules. In these granules, FMRP transports translationally-repressed mRNAs along axons and dendrites to the base of active synapses, where their local translation is a key process for synapse maturation and plasticity (Prieto et al., 2020). The rapid activation of mGlu5 results in FMRP sumoylation at $\mathrm{K} 88$ and $\mathrm{K} 130$, which triggers the dissociation of FMRP from mRNA granules and enables the local translation of mRNAs that control dendritic spine elimination and maturation (Khayachi et al., 2018). It remains to be elucidated whether FMRP sumoylation discharges the whole set of mRNA molecules associated with FMRP or promotes the release of a specific subset of these mRNAs.

\section{Presynaptic sumoylation}

At the presynaptic compartment, sumoylation regulates diverse functions. Synaptosomal fractions loaded with purified SUMO1 display a significant reduction of $\mathrm{Ca}^{2+}$ influx and $\mathrm{KCl}$-evoked glutamate release. Accordingly, $\mathrm{Ca}^{2+}$ influx and $\mathrm{KCl}$-evoked glutamate release are enhanced in synapses supplemented with SENP1 (Feligioni et al., 2009). Intriguingly, modulation of synaptic sumoylation produces the reverse effect on glutamate release evoked by kainate stimulation. These results suggest that different stimuli triggers sumoylation of distinct presynaptic proteins to either inhibit or promote NT release (Feligioni et al., 2009). A primary presynaptic function controlled by the SUMO pathway is SV docking/priming through sumoylation of RIM1 $\alpha$ and synapsin la (SYNla; Fig. 1A). Sumoylation of SYNla triggers its association with SVs and facilitates SV anchoring at the presynaptic membrane (Tang et al., 2015). Similarly, RIM1 $\alpha$ sumoylation at K502 promotes its interaction with the voltage-gated $\mathrm{Ca}^{2+}$ channels $\left(\mathrm{Ca}_{\mathrm{v}}\right)$ 2.1, favoring their clustering at the presynaptic membrane and enhancing the $\mathrm{Ca}^{2+}$ influx required for NT release (Girach et al., 2013). Conversely, non-sumoylated RIM1 $\alpha$ prevents Cav2.1 clustering and increases SV docking in the active zone. Thus, the switch between the sumoylated and non-sumoylated forms of RIM $1 \alpha$ is a key determinant for the fast and synchronous NT release.

Sumoylation also directly controls SV exocytosis by targeting STX1A (Craig et al., 2015; Fig. 1A). Sumoylated STX1A is more associated with two other components of the SNARE complex, SNAP-25 and VAMP-2, providing the mechanical forces required for SV exocytosis. Indeed, preventing STX1A sumoylation reduces its interaction with SNARE proteins and disrupts the balance of SV endo/exocytosis, skewing toward endocytosis.
In 2015, Matsuzaki and colleagues generated a transgenic mouse line overexpressing SUMO1 in neurons aiming to identify the neuronal sumoylome (Matsuzaki et al., 2015). Among the 95 SUMO1 substrates identified by mass spectrometry (MS), only synaptotagmin-1 was further validated biochemically (Fig. 1A). Nevertheless, further investigations are required to exclude possible offtarget sumoylation owing to SUMO1 overexpression.

Regarding mGlu receptors, the majority of Group III were identified as SUMO substrates in primary cultured neurons and heterologous cells (Tang et al., 2005; Seebahn et al., 2008; Dütting et al., 2011; Wilkinson and Henley, 2011; Fig. 1A). mGlu7 is the sole member shown to be sumoylated in brain tissues. Like other SUMO targets, its sumoylation has to be preceded by PKC-dependent phosphorylation at S862 (Choi et al., 2016). Opposed to ubiquitination, mGlu7 sumoylation stabilizes its expression at the cell surface. Therefore, ubiquitination and sumoylation of mGlu7 bidirectionally modulate its surface expression at the presynaptic membrane and ultimately, regulate NT release. The type- 1 endocannabinoid (CB1) receptors are another class of metabotropic receptors that regulates presynaptic functions (Castillo et al., 2012). Interestingly, it was shown that conjugated and unconjugated SUMO1 levels transiently increase upon CB1 activation as well as CB1 itself might be targeted by SUMO (Gowran et al., 2009). However, additional experiments are needed to confirm this hypothesis.

Among the voltage-gated ion channels targeted by sumoylation, potassium channels are the most represented (Fig. 1A). Senp2-deficient mice display hypersumoylation of voltage-gated potassium $\left(K_{\mathrm{V}}\right) 1.1$ and $7.2 / 7.3$ channels. While sumoylation of $K_{v} 1.1$ does not alter channel activity, enhanced sumoylation of $K_{v} 7.2$ reduces depolarizing $M$ currents, resulting in neuronal hyperexcitability and epileptic seizures (Qi et al., 2014). Similarly, sumoylation of surface $\mathrm{K}_{\mathrm{V}} 2.1$ reduces channel activity and, as a consequence, enhances neuronal excitability (Plant et al., 2011). Interestingly, $K_{v} 4.2$ was recently found sumoylated in two distinct sites, producing different effects (Welch et al., 2019). While sumoylation at $K 437$ triggers $K_{v} 4.2$ surface expression, sumoylation at K579 decreases the amplitude of $\mathrm{K}$ currents without any change in $\mathrm{K}_{\mathrm{V}} 4.2$ trafficking. Differently, the sumoylation of voltage-gated sodium ( $\left.\mathrm{Na}_{\mathrm{v}}\right) 1.2$ channels enhances the amplitude of $\mathrm{Na}^{+}$currents (Plant et al., 2016; Fig. 1A).

Sumoylation is also essential to control the axonal trafficking and function of $\mathrm{Na}_{v} 1.7$ by targeting the collapsin response mediator protein 2 (CRMP2; Fig. 1A). CRMP2 is highly expressed in the brain and is critical for microtubule remodeling, neuronal polarity, axon outgrowth, and synapse dynamics (Arimura et al., 2004; Zhang et al., 2016). Expression of a CRMP2 SUMO-deficient mutant prevents its physical interaction with $\mathrm{Na}_{v} 1.7$ and decreases $\mathrm{Na}_{v} 1.7$ surface expression, resulting in reduced amplification of membrane depolarization in presynaptic boutons (Dustrude et al., 2013, 2017; Ju et al., 2013). CRMP2 sumoylation is also phosphorylation dependent (Dustrude et al., 2016). Indeed, interfering with either CRMP2 sumoylation or phosphorylation reduces surface $\mathrm{Na}_{v} 1.7$. CRMP2 
also interacts with the actin cytoskeleton in dendrites and dendritic spines. It was recently found that desumoylation and dephosphorylation of CRMP2 independently promote the formation and maturation of dendritic spines, broadening the importance of PTMs in regulating the multiple functions of CRMP2 (Zhang et al., 2018).

Beside targeted sumoylation, an intriguing concept that might also apply to synapses (Henley et al., 2018) is that sumoylation may occur simultaneously to components of protein assemblies. This idea of a synchronous "SUMO spray" on multiple targets (named "SUMO velcro") was first shown to occur in the nucleus, where DNA damage triggers a SUMO wave that activates multiple components of the enzymatic pathway required to repair the DNA (Psakhye and Jentsch, 2012). Although not yet experimentally validated, the model of SUMO spray might properly suit to presynaptic NT release, which requires a coordinated series of protein-protein interactions that are tightly regulated by sumoylation (Henley et al., 2018).

\section{Postsynaptic sumoylation}

To date, postsynaptic sumoylation has been less characterized than extrasynaptic and presynaptic sumoylation. Nevertheless, the first identified synaptic target of the SUMO pathway was GluK2 (Martin et al., 2007; Figs. 1A, 2). Kainate stimulation promotes GluK2 sumoylation at K886, triggering receptor endocytosis during LTD expression at mossy fiber-CA3 synapses in the hippocampus (Martin et al., 2007; Konopacki et al., 2011; Chamberlain et al., 2012). As for other SUMO targets, the PKC-dependent phosphorylation of S868-GluK2 is required for its subsequent sumoylation (Konopacki et al., 2011; Chamberlain et al., 2012). As aforementioned, GluK2 is also ubiquitinated. However, whether these two PTMs operate in synergy, reciprocally compete or are independent remains to be investigated.

A second postsynaptic SUMO target is the calcium/calmodulin-dependent serine protein kinase (CASK; Fig. 1A). CASK belongs to the membrane-associated guanylate kinase (MAGUK) family of scaffolding proteins and is involved in dendritic spine formation and maturation through the modulation of the actin cytoskeleton via the interaction with the protein 4.1 (Biederer and Südhof, 2001). The protein 4.1 binds spectrin and bridges the association between F-actin and spectrin, stabilizing actin in dendritic spines. Conjugation of SUMO1 to K679 of CASK interferes with the interaction between CASK and protein 4.1 and, consequently, regulates spine density and morphology in developing neurons (Chao et al., 2008).

Among postsynaptic signaling proteins, ARC, which is also ubiquitinated, is the sole SUMO target identified so far (Craig and Henley, 2012; Craig et al., 2012; Figs. 1A, 2). The expression of a constitutively desumoylated ARC selectively prevents the increase of surface AMPARs during TTX-induced synaptic up-scaling, indicating that sumoylation inhibits ARC function. Interestingly, the same treatment also augments the amount of SUMO1-conjugated proteins and decreases SENP1 levels (Craig et al., 2012). Recently, it was demonstrated that sumoylated
ARC is more broadly implicated in synaptic plasticity. During LTP consolidation, sumoylated ARC selectively accumulates in synaptosomal and cytoskeletal fractions, where it forms a complex with the F-actin binding protein drebrin A, stabilizing nascent actin filaments in dendritic spines (Nair et al., 2017). These results further support the role of sumoylation as master regulator of different forms of synaptic plasticity.

At inhibitory synapses, gephyrin is extensively subjected to PTMs (Tyagarajan and Fritschy, 2014). In 2016, it was shown that gephyrin sumoylation at K148 and K724 negatively regulates its postsynaptic clustering and, ultimately, reduces synapse formation and inhibitory transmission (Fig. 1C). Gephyrin sumoylation is intimately linked to other PTMs, which synergistically operate to orchestrate its clustering dynamics (Ghosh et al., 2016). Desumoylation of gephyrin at K148 leads to deacetylation at K666 and dephosphorylation at $\mathrm{S} 268$ residues, enhancing its postsynaptic clustering and the assembly of inhibitory synapses.

Recently, the presence of SUMO1-conjugated proteins at synapses was questioned, bringing out an intense scientific debate on this topic (Tirard et al., 2012; Daniel et al., 2017, 2018; Wilkinson et al., 2017). By using KI mice expressing $\mathrm{His}_{6}-\mathrm{HA}-\mathrm{SUMO1}$, Dr. Brose and Dr. Tirard teams were not able to validate sumoylation of seven previously characterized presynaptic and postsynaptic SUMO targets nor to observe SUMO1 conjugation at synapses (Daniel et al., 2017). On the contrary, they could confirm that extrasynaptic/nuclear sumoylation is present (Tirard et al., 2012), concluding that there is no evidence of synaptic SUMO1-ylation. Notwithstanding, several arguments support the presence of SUMO1-ylation at the synapse questioning whether this animal model is suitable to study sumoylation. (1) In $\mathrm{His}_{6}-\mathrm{HA}-\mathrm{SUMO} 1 \mathrm{KI}$ mice, there is $20-$ $30 \%$ less SUMO1 conjugation than WT mice, and this impairment is associated to a significant increase of SUMO2/ 3-conjugated proteins (Tirard et al., 2012; Daniel et al., 2017). This reduction in the efficiency of SUMO1 conjugation could make particularly challenging the detection of SUMO targets in the synaptic compartment where sumoylation is already low and extremely transient; (2) a wealth of studies confirmed the functional relevance of synaptic sumoylation (e.g., use of non-sumoylatable mutants), while Daniel and colleagues did not carry out this analysis (for review, see Henley et al., 2018; Schorova and Martin, 2016); (3) consistent data clearly indicate the presence of components of the SUMO machinery at synaptic sites (Watanabe et al., 2008; Loriol et al., 2012, 2014; Hasegawa et al., 2014; Josa-Prado et al., 2019; Schorova et al., 2019); (4) some key technical differences may explain the failure to detect synaptic sumoylation (e.g., weak SUMO1 immunostaining and the use of antibodies that do not recognize sumoylated proteins). Although in our opinion substantial data indicate the presence and the functional relevance of synaptic SUMO1-ylation, the aforementioned studies pointed out the need of defining strict consensus criteria to investigate sumoylation in the brain.

\section{Neddylation}

Neddylation consists in the covalent and reversible attachment of a NEDD8 (for neural precursor cell 
expressed, developmentally downregulated 8) moiety to a $\mathrm{K}$ residue of target proteins. Of the UBLs, NEDD8 shows the greatest degree of similarity with ubiquitin ( $~ 80 \%)$. Like ubiquitination and other UBLs, neddylation requires a three-step enzymatic cascade to activate and covalently attach NEDD8 to $\mathrm{K}$ residues of target proteins (Enchev et al., 2015). While E1 activating and E2 conjugating enzymes have been identified (NEDD8 activating enzyme, NAE as E1, and UBC12 and UBE2F as E2 enzymes), the E3 ligases are as yet ill-defined. Deconjugation of NEDD8 from targets is achieved by NEDD8-specific proteases, namely the metalloprotease CSN5, the cysteine protease NEDP1 and USP21 (Enchev et al., 2015).

Although NEDD8 function and regulation remain largely unexplored, recent papers shed light on the importance of neddylation in synaptic maturation, function and plasticity. Neddylation is observed during embryonic brain development, its expression increases during the first two postnatal weeks and is then maintained throughout adulthood (Kumar et al., 1992; Vogl et al., 2015). As the best characterized function of NEDD8 involves the activation of ubiquitin E3 ligases of the Cullin-RING family (Fig. 1A), neddylation is thought a major regulator of ubiquitination (Enchev et al., 2015). In the hippocampus, NMDAR-dependent neddylation promotes the UPS-dependent degradation of the DNA methyltransferase DNMT3a1 leading to demethylation of the BDNF promoter and enabling BDNF expression during memory consolidation (Fig. 1A; Bayraktar et al., 2019). Among the members of the cullinRING family, several ligases mediate the targeted degradation of synaptic elements and negatively regulate synapses (e.g., cullin3 and parkin). However, inhibition of the neddylation pathway does not enhance synaptic activity and strength as it would have been expected as a consequence of reduced synaptic ubiquitination. Instead, it destabilizes dendritic spines, affects synaptic transmission and plasticity, and impairs cognitive functions (Scudder and Patrick, 2015; Vogl et al., 2015; Brockmann et al., 2019), thus suggesting that neuronal neddylation targets other substrates relevant to synaptic function. In line with this, Vogl and colleagues elegantly demonstrated that PSD-95 is neddylated at K202 by MDM2 (Vogl et al., 2015), which also mediates PSD-95 ubiquitination (Fig. 1A; Colledge et al., 2003; Bianchetta et al., 2011). Although PSD-95 neddylation does not modify its ubiquitination and degradation rate, neddylation reduces synaptic clustering of PSD-95. Furthermore, the expression of a non-neddylatable mutant recapitulates at least some of the molecular and cellular phenotypes observed with PSD-95 knockdown (Ehrlich et al., 2007), indicating that NEDD8-conjugation is required for PSD-95 proactive functions. PSD-95 is a major molecular hub of excitatory synapses and mediates multiple interactions with several proteins (Sheng and Kim, 2011). How neddylation changes PSD-95 conformation and/or affinities with its partners remains to be uncovered. Very recently, a NEDD8-ubiquitin substrate profiling detected 341 neddylated proteins in HEK293 cells expanding the repertoire of neddylated targets and indicating broader roles of neddylation than the sole activation of cullin-RING E3 ligases (Vogl et al., 2020). Among the identified targets, the authors biochemically and functionally characterized cofilin neddylation in the brain and found that it is required to ensure proper dendrite development in mouse cortical neurons (Fig. 1A; Vogl et al., 2020).

\section{ID and Impairment of Ubiquitination and Sumoylation Pathways}

ID is a neurodevelopmental disorder with an estimated prevalence of $1-3 \%$. The formal diagnosis of ID is based on the intelligence quotient (IQ) test, which should be scored $<70$, and the presence of deficits in at least two adaptive behaviors that affect everyday activities. It is classified as mild, moderate, severe, or profound based on IQ score. ID is defined as non-syndromic if the intellectual deficit is the sole clinical feature, or as syndromic if the mental impairment is comorbid with other neurologic pathologies such as epilepsy, sensory alterations and ASD (llyas et al., 2020). ID is a complex multifactorial disease, in which environmental and genetic factors and their reciprocal interaction critically contribute to its etiology. Yet, $25 \%$ of ID cases have clear genetic origins and some of these forms are monogenic. The environmental factors that underlie ID comprise stressful events occurring at early stages of neurodevelopment, including drug and alcohol abuse and infections during pregnancy, birth complication, and severe malnutrition. Thanks to recent advances in whole-genome sequencing, the identification of genetic defects is becoming increasingly efficient. To date, $\sim 700$ genes were associated to either syndromic or non-syndromic ID. Notably, more than $50 \%$ of these genes encode presynaptic or postsynaptic proteins, or proteins implicated in synapse development, function and plasticity (llyas et al., 2020). Among the several genes associated with ID, 100 genes are located on chromosome (chr.) $X$ and are responsible for X-linked ID (XLID; Ropers and Hamel, 2005).

Numerous ID-associated genes code for proteins targeted by ubiquitination and sumoylation or components of ubiquitin and SUMO machineries. Furthermore, some extrinsic risk factors of ID seem to be associated with alterations of brain ubiquitome and/or sumoylome. As described above, several studies indicate that ubiquitination and sumoylation are critical to the expression of synaptic plasticity, the cellular correlate of learning and memory processes and whose impairment is a major hallmark of ID (Aicardi, 1998). Collectively, this evidence suggests that ubiquitination and sumoylation failure may be implicated in ID pathogenesis. Despite pharmacological or genetic blockade of neddylation results in cognitive dysfunctions that may manifest in ID patients (e.g., impaired memory and sociability; Vogl et al., 2015), current evidence does not indicate a direct involvement of neddylation in the development of ID. Below, we provide an overview of the ID forms that are linked to defective ubiquitin and SUMO pathways.

\section{Ubiquitination and ID}

Beyond the well-established role of ubiquitination in synapse physiology, its dysregulation has been largely linked to synaptic dysfunction and ID pathogenesis (Mabb and Ehlers, 2010; Upadhyay et al., 2017; George et al., 2018). As listed in Table 1, causal genes directly 
Table 1: Rare monogenic forms of ID linked to mutations of components or regulators of the ubiquitin pathway

\begin{tabular}{|c|c|c|c|c|}
\hline Gene & Protein & Disease & Genetic abnormalities & References \\
\hline$\overline{A S X L 3}$ & $\begin{array}{l}\text { Component of the Polycomb } \\
\text { repressive deubiquitination } \\
\text { (PR-DUB) complex }\end{array}$ & $\begin{array}{l}\text { Bainbridge-Ropers syndrome, BRS } \\
\text { (OMIM 615485) and ASD }\end{array}$ & $\begin{array}{l}\text { De novo truncating muta- } \\
\text { tions in BRS and mis- } \\
\text { sense mutations in ASD }\end{array}$ & $\begin{array}{l}\text { Bainbridge et al. } \\
\text { (2013); De } \\
\text { Rubeis et al. } \\
\text { (2014) }\end{array}$ \\
\hline CUL4B & $\begin{array}{l}\text { Scaffolding protein stabilizing } \\
\text { cullin RING E3 ligase }\end{array}$ & XLID (OMIM 300304) & Missense mutations & $\begin{array}{l}\text { Wang et al. (2013); } \\
\text { Zou et al. (2007) }\end{array}$ \\
\hline HECW2 & E3 ubiquitin ligase HECW2 & $\begin{array}{l}\text { Neurodevelopmental disorder with hypo- } \\
\text { tonia, seizures, and absent language, } \\
\text { NDHSAL (OMIM 617268) }\end{array}$ & Missense mutations & $\begin{array}{l}\text { Halvardson et al. } \\
\qquad(2016)\end{array}$ \\
\hline HERC1 & E3 ubiquitin ligase HERC1 & $\begin{array}{l}\text { Macrocephaly, dysmorphic facies, and } \\
\text { psychomotor retardation, MDFPMR } \\
\text { (OMIM 617011) }\end{array}$ & $\begin{array}{l}\text { Missense and frameshift } \\
\text { mutations }\end{array}$ & $\begin{array}{l}\text { Aggarwal et al. } \\
\text { (2016); Nguyen } \\
\text { et al. (2016); } \\
\text { Ortega-Recalde } \\
\text { et al. (2015) }\end{array}$ \\
\hline HERC2 & E3 ubiquitin ligase HERC2 & $\begin{array}{l}\text { Syndrome of ID, autism, and variable } \\
\text { neurological deficits (OMIM 615516) }\end{array}$ & Missense mutations & $\begin{array}{l}\text { Puffenberger et al. } \\
\text { (2012) }\end{array}$ \\
\hline MAGEL2 & E3 ubiquitin ligase enhancer & $\begin{array}{l}\text { Prader-Willi syndrome, PWS (OMIM } \\
\text { 176270) and Schaaf-Yang syndrome, } \\
\text { SHFYNG (OMIM 615547) }\end{array}$ & $\begin{array}{l}\text { Interstitial deletions and } \\
\text { maternal uniparental } \\
\text { disomy in PWS; trun- } \\
\text { cating mutations in } \\
\text { SHFYNG }\end{array}$ & $\begin{array}{l}\text { Tacer and Potts } \\
(2017)\end{array}$ \\
\hline MID2 & $\begin{array}{l}\text { Member of the TRIpartite } \\
\text { motif (TRIM) family of RING } \\
\text { E3 ligases }\end{array}$ & XLID (OMIM 300928) & Missense mutation & $\begin{array}{l}\text { Geetha et al. } \\
\text { (2014) }\end{array}$ \\
\hline OTUD6B & $\begin{array}{l}\text { Member of the ovarian tumor } \\
\text { domain (OTU)-containing } \\
\text { subfamily of deubiquitinat- } \\
\text { ing enzymes }\end{array}$ & $\begin{array}{l}\text { Intellectual developmental disorder with } \\
\text { dysmorphic facies, seizures, and distal } \\
\text { limb anomalies, IDDFSDA (OMIM } \\
617452 \text { ) }\end{array}$ & $\begin{array}{l}\text { Truncating and missense } \\
\text { mutations }\end{array}$ & $\begin{array}{l}\text { Santiago-Sim et } \\
\text { al. (2017) }\end{array}$ \\
\hline PLAA & $\begin{array}{l}\text { Ubiquitin binding protein } \\
\text { phospholipase A2 activat- } \\
\text { ing protein }\end{array}$ & $\begin{array}{l}\text { Neurodevelopmental disorder with pro- } \\
\text { gressive microcephaly, spasticity, and } \\
\text { brain anomalies, NDMSBA (OMIM } \\
617527 \text { ) }\end{array}$ & Missense mutations & $\begin{array}{l}\text { Falik Zaccai et al. } \\
\text { (2017); Hall et } \\
\text { al. (2017) }\end{array}$ \\
\hline TRIP12 & $\begin{array}{l}\text { Member of the HECT domain } \\
\text { E3 ubiquitin ligases family }\end{array}$ & ID with or without ASD (OMIM 6177520) & $\begin{array}{l}\text { CNVs, missense, frame- } \\
\text { shift, splicing mutations }\end{array}$ & Zhang et al. (2017) \\
\hline UBE2A & $\begin{array}{l}\text { E2 ubiquitin conjugating en- } \\
\text { zyme E2A }\end{array}$ & $\begin{array}{l}\text { XLID type Nascimento } \\
\text { (OMIM 300860) }\end{array}$ & $\begin{array}{l}\text { Truncating and missense } \\
\text { mutations }\end{array}$ & $\begin{array}{l}\text { Budny et al. } \\
\text { (2010); } \\
\text { Nascimento et } \\
\text { al. (2006) }\end{array}$ \\
\hline UBE3B & E3 ubiquitin ligase E3B & $\begin{array}{l}\text { Blepharophimosis-ptosis-ID syndrome, } \\
\text { BPIDS (OMIM 244450) }\end{array}$ & Truncating mutations & $\begin{array}{l}\text { Basel-Vanagaite } \\
\text { et al. (2012) }\end{array}$ \\
\hline USPX9 & $\begin{array}{l}\text { Deubiquitinating enzyme } \\
\text { FAF-X }\end{array}$ & $\begin{array}{l}\text { Female-restricted X-linked non-syn- } \\
\text { dromic mental retardation-99 (OMIM } \\
\text { 300919) }\end{array}$ & $\begin{array}{l}\text { Truncating mutation and } \\
\mathrm{X} \text {-chr. deletion }\end{array}$ & Au et al. (2017) \\
\hline
\end{tabular}

XLID: X-linked ID, CNV: copy number variation.

encode either components of the ubiquitin machinery or regulators of ubiquitination (PLAA and MAGEL2 genes). A third category, not discussed here for space constraints comprises genes encoding targets of ubiquitination in which pathogenic mutations may change their ubiquitination profile. The molecular mechanisms underlying the function of the first two categories of genes and the neuronal substrates that they target are poorly characterized.
For these reasons, the molecular pathogenesis of these forms of ID is unclear.

In general, ubiquitin-linked ID forms present comorbidities that are commonly present in ID. Mental impairment is often accompanied by dysmorphic features and multiple neurologic and neuropsychiatric manifestations (e.g., epilepsy, motor dysfunction, and autistic behaviors). Many syndromes are also multisystem disorders underscoring 
the ubiquitous importance of ubiquitination for tissue and body formation and function. To the best of our knowledge, a clear classification of ID forms, and more generally of brain disorders linked to defective ubiquitination, does not exist. Functional and genetic groups may be however elaborated. For instance, a genetic classification may be based on components of the enzymatic cascade mediating the different steps of ubiquitin conjugation/deconjugation (e.g., E2-E3, and DUB enzymes). Functional classes may include ubiquitinating enzymes involved in distinct cellular functions, such as regulation of transcription, trafficking, cell division or proteasome activity. Although other criteria may certainly be applied to propose alternative classifications including comorbidities, no unique behavioral phenotypes associate with any of the aforementioned groups. Overall, it clearly emerges that ubiquitination and its delicate homeostasis are fundamental for brain physiology. Indeed, the perturbation of this equilibrium caused by the altered expression or activity of a single E3 ubiquitin ligase is hardly compensated by the other $\sim 600 \mathrm{E} 3$ and is sufficient to lead to severe pathologic states of the brain. Here, we discuss in more details the implications of defective ubiquitination in the molecular pathogenesis of two of the most common forms of syndromic ID, the AS and Down syndrome (DS).

\section{Angelman syndrome}

AS (OMIM 105830) is a relatively rare neurodevelopmental disorder (prevalence of 1/15,000 live births) characterized by severe intellectual deficit, motor dysfunction, unusually happy demeanor, seizures and autism-like behavior (Clayton-Smith and Laan, 2003; Margolis et al., 2015; Buiting et al., 2016). AS results from distinct genetic abnormalities that ultimately lead to the loss of the brainspecific imprinted UBE3A (ubiquitin protein ligase E3A, also referred to as E6AP) gene (Mabb et al., 2011). UBE3A encodes three isoforms that are generated by alternative splicing and localize either in the nucleus or cytosol (Miao et al., 2013). In the cytosol, UBE3A is found in axonal terminals and dendritic spines (Dindot et al., 2008; Burette et al., 2018). While UBE3A loss results in AS, elevated expression or activity of $U B E 3 A$ represent the most identifiable genetic form of ASD, indicating that a tight balance in the dosage of this gene is critical to develop functional neuronal circuits.

Data from AS mouse models suggest that UBE3A plays a key role in modulating synaptic pathways important for cognition and behavior. Neurons from Ube3a-KO mice display abnormal dendritic spines, reduced excitatory neurotransmission and impaired synaptic plasticity (Dindot et al., 2008; Yashiro et al., 2009; Pignatelli et al., 2014; Kim et al., 2016; Avagliano Trezza et al., 2019; Wang et al., 2019a). Given the primary function of UBE3A as E3 ubiquitin ligase, defective ubiquitination is thought to be at the basis of neuronal dysfunctions and clinical manifestations of AS. However, only a few substrates have been identified and shown to be functionally relevant to AS etiology. For these reasons, the molecular underpinnings of UBE3A function remain enigmatic. Different mechanisms, mainly driven by the defective ubiquitination hypothesis, have been put forward on the pathogenic role of UBE3A. (1) In physiological conditions, UBE3A may indirectly modulate the number of AMPARs at the postsynaptic membrane by ubiquitinating the aforementioned signaling protein $A R C$ and promoting its degradation (Greer et al., 2010). Therefore, loss of UBE3A may increase ARC levels and lead to enhanced AMPAR internalization and, ultimately, depression of glutamatergic transmission. (2) A second synaptic substrate of UBE3A is ephexin 5 (Margolis et al., 2010). Ephexin 5 is a guanine nucleotide exchange factor (GEF) activator of the RhoA GTPase that limits the number of excitatory synapses via inhibition of the synaptogenic, trans-synaptic EphB receptor/ephrin ligand complex (Henderson and Dalva, 2018). Ube3a-KO mice display increased amounts of ephexin 5 and abnormal density of excitatory synapses, indicating that UBE3A-dependent degradation of ephexin 5 is critical for the normal development of excitatory synapses. (3) A recent study suggested that UBE3A ubiquitinates the small conductance potassium channel SK2, whose major function is to repolarize neuronal membranes after depolarization (Ngo-Anh et al., 2005) and facilitates its endocytosis (Sun et al., 2015b). In line with defective ubiquitination of SK2, its surface expression is significantly increased in Ube3a-KO mice, resulting in membrane hyperpolarization and impaired synaptic plasticity. (4) A role for CAMKII was proposed based on the observation that hippocampi derived from AS mice display reduced CAMKII activity and excessive inhibitory autophosphorylation (Weeber et al., 2003). In particular, the correction of some AS neurologic deficits obtained preventing CAMKII inhibitory autophosphorylation suggests that CAMKII may be instrumental to UBE3A-dependent pathways underlying AS phenotype (van Woerden et al., 2007). However, it is not known whether UBE3A directly targets CAMKII for degradation or targets unknown kinases or phosphatases that in turn modulate CAMKII phosphorylation. Strikingly, PTPA, which is the activator of a major phosphatase of CAMKII, PP2A, was recently identified as UBE3A target (Wang et al., 2019a). However, the modulation of PTPA levels does not affect the phosphorylation of CAMKII, suggesting other downstream substrates. (5) In cerebellar Purkinje cells of AS mice, mechanistic target of rapamycin (mTOR) signaling is unbalanced, resulting in upregulated $\mathrm{mTORC} 1$ and reduced mTORC2 (Sun et al., 2015a). mTORC1 activation relies on its lysosomal recruitment through the interaction with the Rag GTPase-Ragulator complex. UBE3A ubiquitinates the p18 subunit of the Ragulator complex. Therefore, in AS mouse models defective p18 ubiquitination enhances mTORC1 activity by increasing its lysosomal recruitment. (6) A recent proteomic-based study aimed at identifying new UBE3A substrates implicated autophagy in AS pathogenesis (Wang et al., 2019b). UBE3A physically associates with and ubiquitinates the autophagy regulator Huntington-associated protein 1 (HAP1), a key protein for autophagosome trafficking. In AS mouse model, increased HAP1 leads to excessive autophagy and ultimately, dendritic spine defects. Consistently, pharmacological attenuation of autophagy partially alleviates synaptic dysfunction and behavioral deficits in AS mice. 
The above studies have focused on mechanisms underlying weakened excitatory synapses. However, the vast majority of AS patients display autistic behavior and seizure susceptibility (Clayton-Smith and Laan, 2003), suggesting that loss of UBE3A may increase the excitation (E)/ inhibition (I) ratio in the neocortex. Recent evidence proposed that UBE3A loss might impact GABAergic neurons more severely than the excitatory counterpart, with the potential net outcome favoring hyperexcitability (Wallace et al., 2012; Judson et al., 2016). Future studies aimed at investigating whether UBE3A directly operates at inhibitory synapses and which are its substrates will help clarifying UBE3A-mediated mechanisms modulating neuronal excitability.

Together, these studies clearly indicate that UBE3A regulates several cellular pathways that critically contribute to synapse development and function, and that altered ubiquitination is central to AS etiology. Although the number of identified UBE3A substrates is rapidly increasing, the functional relevance of these interactions is not clear yet and an integrated picture of UBE3A function is lacking. In addition, the weight of individual substrates and pathways in the pathogenesis of AS and its clinical manifestations is still enigmatic.

\section{Down syndrome}

DS (OMIM 190685) is the most common cause of ID and accounts for $\sim 15-20 \%$ of all individuals affected by ID. DS is a complex genetic disorder characterized by heterogenous clinical manifestations. Among them, cognitive impairment is present in all DS individuals (Antonarakis et al., 2004). The DS critical region (DSCR) is a relatively small locus on chr.21, and its triplication is necessary and sufficient to generate DS cognitive deficits. One of the genes localized in the DSCR is TTC3, which is consistently upregulated in patients and animal models of DS (Saran et al., 2003). TTC3 encodes an E3 ubiquitin ligase that targets a phosphorylated form of the kinase AKT (Suizu et al., 2009), which is critical for several cellular functions in the brain (Hers et al., 2011). In Ts65Dn mice, the most common animal model of DS, the abnormal levels of TTC3 enhance ubiquitination and degradation of AKT. Among its multiple synaptic functions, AKT phosphorylates the $\beta$ subunits of $\mathrm{GABA}_{\mathrm{A}} \mathrm{Rs}$ in hippocampal neurons, thereby increasing the number of surface $\mathrm{GABA}_{A}$ Rs at inhibitory synapses (Wang et al., 2003). Remarkably, DS individuals show a higher incidence of seizures, raising the possibility that enhanced TTC3mediated degradation of AKT leads to the loss of E/I equilibrium in the brain and hyperexcitability. In developing neurons, TTC3 overexpression also limits neurite outgrowth and modifies the morphology of the Golgi apparatus through the modulation of actin-regulating pathways (Berto et al., 2014). Strikingly, TTC3 also significantly correlates with other DS-unrelated brain pathologies associated with ID, suggesting an essential role for TTC3 in complex cognitive functions (Vilardell et al., 2011).

Dysfunctions of global neuronal ubiquitome in DS are also detected in aged Ts65Dn mice and postmortem brains of DS patients. Such alterations are linked to the accumulation of inclusion bodies in the cerebellum, a cellular hallmark of Alzheimer's disease (AD), a neurodegenerative disorder that is particularly frequent in DS (Necchi et al., 2011; Tramutola et al., 2017). On the other hand, it was reported that in both DS patients and Ts65Dn mice the USP16 gene, which maps on chr.21 and codes for a deubiquitinase, is critical to DS pathogenesis (Adorno et al., 2013). USP16 triplication excessively removes ubiquitin from histone $\mathrm{H} 2 \mathrm{~A}$, a key event for the self-renewal and expansion of different progenitor cells, including neuronal progenitors. In line with this, a reduced expansion of postnatal neuronal progenitors is observed in DS patients.

All of these pieces of evidence suggest that unbalanced ubiquitination critically contributes to neuronal circuit dysregulation and clinical manifestations of DS, including ID. The relative contribution of these pathways to the molecular pathogenesis of DS remains largely unknown.

\section{Sumoylation and ID}

As aforementioned, sumoylation is critical to build up proper synaptic connections by modulating the function of several neuronal proteins. The evidence that several SUMO targets are ID-associated proteins raises the possibility that impaired sumoylation may be relevant to ID etiology. An increasing number of molecular studies now supports this hypothesis and suggests that dysregulated neuronal sumoylation may participate to the development of two common syndromic forms of ID, the RTT and DS. Furthermore, defective sumoylation may potentially be implicated in other ID forms, such as Fragile $X$ syndrome (FXS), Phelan-McDermid syndrome (PMS) and the Cc2d1-dependent non-syndromic ID.

\section{Rett syndrome}

RTT (OMIM 312750) is a devastating neurodevelopmental disorder and the leading cause of genetic ID in young girls. Almost $95 \%$ of RTT individuals carry mutations in the MECP2 gene. As described above, MECP2 is sumoylated at K223 and K412 residues and these modifications regulate the activity of MECP2 as transcriptional repressor. The analysis of sumoylation profiles of seven different mutated MECP2 variants identified in RTT patients reveals that six of these mutations decrease MECP2 sumoylation because of a lower affinity for the SUMO E3 ligase PIAS1 (Tai et al., 2016). Strikingly, while the lentiviral expression of either WT or sumoylated MECP2 in conditional Mecp2-KO mice restores some cellular and behavioral deficits, such as social interaction, fear memory and LTP, the expression of a non-sumoylatable MECP2 mutant fails to rescue these phenotypes. In this study, it was also demonstrated that these pathologic mutations are associated with altered MECP2 phosphorylation at S421, a PTM that is known to promote its sumoylation. In the same study, the authors also demonstrated that mice expressing non-sumoylatable MECP2 display 12-fold decrease in Wnt6 mRNA levels compared to WT animals. Very recently, the same group showed that lentiviral expression of WNT6 rescues defective MECP2 sumoylation in MECP2 T158A mouse model of RTT. Wnt6 transduction and enhanced MECP2 
sumoylation also resulted in partial amelioration of locomotor and social behavioral deficits (Hsu et al., 2020). Together, these pioneer studies provided for the first time a link between altered sumoylation and the etiology of ID, representing an important milestone in the field.

\section{ID linked to SUMO machinery-encoding genes}

Since the SUMO3 paralogue gene is located in the long arm of chr.21, the excessive dosage of SUMO3 is an intriguing hypothesis in DS pathogenesis. Several transcriptional factors and the glucocorticoid receptor, which are known to control cognitive functions, are targeted by SUMO3 (Schorova and Martin, 2016). In line with this, the levels of free and conjugated SUMO2/3 proteins are significantly higher in hippocampal lysates derived from DS patients compared with healthy individuals (Gardiner, 2006). Yet, a comprehensive view of SUMO3 neuronal targets is lacking and the impact of SUMO3 triplication on DS etiology remains elusive. Recently, Binda and colleagues reported a marked decrease of the SUMO2/3specific deconjugating enzyme SENP3 in DS patients without any corresponding increase of SUMO2/3-conjugated proteins (Binda et al., 2017). Future studies aiming at systematically analyzing $\mathrm{SUMO} 3$ substrates in the brain will be of invaluable help to elucidate the role of enhanced sumoylation in DS pathogenesis.

A woman with profound developmental delay associated with several other clinical manifestations was found to carry a microdeletion in the chr.19 that resulted in the haploinsufficiency of 15 genes, including $S A E 1$, a subunit of the SUMO1 activating enzyme (Leal et al., 2009). Although the authors suggested that the loss of SAE1 gene may correlate with an impaired development of the cleft lip and palate, it remains to be determined whether this alteration might also participate to other pathologic features, comprising defective cognitive functions.

ZMIZ1 gene codes for an androgen receptor coactivator that functions as an E3 SUMO ligase (Sharma et al., 2003) and recently identified mutations were associated with ID and developmental delay (Carapito et al., 2019). Notably, all identified ZMIZ1 mutations occur in the SUMO acceptor site, suggesting that they might compromise the E3 SUMO ligase activity of ZMIZ1, resulting in a failure of sumoylation homeostasis in neurons.

\section{Cc2d1-dependent non-syndromic ID}

Mutations in the Coiled-coil and $\mathrm{C} 2$ domain containing $1 \mathrm{~A}(C C 2 D 1 A)$ gene are associated with non-syndromic ID (OMIM 608443). This gene codes for CC2D1A, a DNA binding protein that regulates multiple cellular signaling pathways, including serotonin and dopamine receptors, dendritic arborization, synapse maturation, and plasticity (Zhao et al., 2011; Al-Tawashi et al., 2012; Manzini et al., 2014; Oaks et al., 2017; Yang et al., 2019). Consistent with these roles, the loss of CC2D1A in vivo determines the appearance of cognitive and social deficits (Oaks et al., 2017). Very recently, it was shown that conditional deletion of Cc2d1a in excitatory neurons of the forebrain leads to decreased levels of SENP1 and SENP3. As a consequence, the desumoylation of the small GTPase RAC1, one of the major targets of SENP1 and SENP3, is suppressed (Yang et al., 2019). Since RAC1 activity is enhanced by sumoylation, hyperactived RAC1 results in abnormal dendritic morphology and synaptic dysfunction. Remarkably, pharmacological blockade of RAC1 activity partially rescues deficits in synaptic plasticity and memory observed in Cc2d1a-cKO mice (Yang et al., 2019). In conclusion, this work provides further experimental evidence supporting the hypothesis that aberrant sumoylation is a key molecular determinant underlying ID etiology.

\section{mGlu5-related IDs: Phelan-McDermid and Fragile X} syndromes

PMS and FXS are two major forms of ID and are associated with dysregulation of the mGlu5-dependent pathway. The loss of SHANK3 gene, which is caused by deletions of the terminal end of chr.22 long arm, is critical to PMS development. SHANK3 is a major scaffolding protein of excitatory synapses that anchors, together with HOMER1, mGlu5 to the postsynaptic membrane. As a consequence, the loss of Shank3 impairs mGlu5 activity by destabilizing the pool of surface receptors (Vicidomini et al., 2017). Conversely, FXS mouse models carrying loss-of-function mutations of Fmr1 gene are characterized by excessive mGlu5-dependent signaling (Prieto et al., 2020).

Considering the functional relevance of mGlu5 to SUMO homeostasis (Loriol et al., 2014; Schorova et al., 2019), the analysis of brain sumoylome in animal models of PMS and FXS is of primary importance and might uncover pivotal roles of sumoylation in the molecular pathogenesis of these neurodevelopmental disorders. Recently, new evidence further supported the possibility that sumoylation might be a key determinant in the pathogenesis of FXS (Khayachi et al., 2018; Prieto et al., 2020). The novel pathologic missense mutation $\mathrm{R} 138 \mathrm{Q}$ of $F M R 1$ gene was identified in three unrelated individuals presenting developmental delays, ID, and seizures (Collins et al., 2010; Diaz et al., 2018; Sitzmann et al., 2018). In contrast to other FXS cases, this mutation does not affect the expression levels of FMRP protein. As the R138Q mutation localizes in close proximity to the SUMO site $\mathrm{K} 130$ of FMRP, it is possible that the R138Q mutation causes aberrant FMRP sumoylation, and this impairment may be causative of FXS. Similarly, the F126S mutation, which was reported in a FXS male patient presenting ID and autistic features (Quartier et al., 2017), also localizes nearby $\mathrm{K} 130$ residue. As this mutation replaces a phenylalanine $(\mathrm{F})$ with an $S$ residue, it likely generates a novel phosphorylation site, which could subsequently promote sumoylation at K130 (Loriol et al., 2014). Further studies are required to better explore this hypothesis.

\section{Functional Interplay Between Ubiquitination and UBLs}

Recently, the existence of a dynamic interplay between ubiquitination and UBLs provided an intriguing perspective that could lead to the identification of novel principles underlying synapse development and function. As mentioned above, the best characterized function of NEDD8 is to enhance the activity of Cullin E3 ligases providing evidence of a direct interaction with ubiquitination (Enchev et al., 2015). Moreover, neddylation-dependent ubiquitination 
and degradation of DNMT3a1 is critical to increase BDNF expression and is required to memory consolidation in the hippocampus (Bayraktar et al., 2019). PSD-95 is targeted by the E3 ligase MDM2, which mediates both ubiquitination and neddylation (Colledge et al., 2003; Bianchetta et al., 2011; Vogl et al., 2015). However, neddylation does not change PSD-95 degradation rate (Vogl et al., 2015), and the possible cross talk between these two PTMs on PSD95 remains unknown. Altogether, more study is needed to better understand neddylation and its interplay with other PTMs.

Emerging evidence also indicates that ubiquitination and sumoylation reciprocally interact to precisely regulate protein function. Numerous neuronal substrates are targeted by both ubiquitin and SUMO machineries. Proteomic approaches showed that $\sim 25 \%$ of SUMO-acceptor K residues are also ubiquitinated, suggesting that these two pathways likely compete with each other for the same $\mathrm{K}$ residues (Tammsalu et al., 2014). However, a few examples suggest that this interplay is not only antagonistic, but ubiquitination and sumoylation can also operate in synergy. The hypoxia-inducible factor $1 \alpha(\mathrm{HIF} 1 \alpha)$ requires to be sumoylated for its subsequent UPS-dependent degradation (Cheng et al., 2007). Similarly, the sequential sumoylation and ubiquitination of the serine hydroxymethyltransferase 1 (SHMT1) and the regulatory subunit of the kinase IKK are required to control the rate of nuclear import/export of these proteins and, ultimately, to regulate their activity (Huang et al., 2003; Anderson et al., 2012). Moreover, the impairment of ubiquitination/sumoylation cross talk critically contributes to the development of neurodegenerative disorders. For instance, in $A D$, this interplay is critical for the formation of tau-containing neurofibrillary tangles, a primary hallmark of AD. Indeed, hyperphosphorylation of tau protein enhances its sumoylation in a $\beta$-amyloid $(\mathrm{A} \beta)$-dependent manner. Once sumoylated, tau is less ubiquitinated and degraded, favoring tau aggregation and decreasing its solubility (Luo et al., 2014). Another neurodegenerative disorder in which the competition between ubiquitination and sumoylation is relevant for disease pathogenesis is Huntington's disease $(H D)$. HD is caused by the expansion of huntingtin $(\mathrm{HTT})$ polyglutamine repeats. Proteolytic cleavage of mutated HTT generates a pathogenic fragment (HTTEX1P) that creates toxic aggregates in the nucleus and cytoplasm. Both ubiquitination and sumoylation target K6 and K9 of the HTTEX1P fragment and mediate opposite effects. Sumoylation increases HTTEX1P stability and aggregation, its function as transcriptional repressor and ultimately, its neurotoxicity (Steffan et al., 2004). Conversely, ubiquitination reduces HTTEX1P neurotoxicity probably by promoting its degradation (Kalchman et al., 1996). Consistent with this, in a Drosophila model of HD, sumoylation and ubiquitination of HTTEX1P worsen and abrogate neurodegeneration, respectively (Steffan et al., 2004).

To date, the functional interplay between ubiquitination and sumoylation in ID pathogenesis has been poorly characterized. Growing evidence suggests that a defective cross talk might underlie, at least partially, synaptic dysfunction observed in certain forms of ID. As described above, SUMO3, the E3 ubiquitin ligase TTC3 and the deubiquinating enzyme USP16 are located within the DSCR and are triplicated in DS individuals (Adorno et al., 2013; Gardiner, 2006; Saran et al., 2003). The hyperabundance of SUMO3 could either decrease the ubiquitination of those substrates for which ubiquitination and sumoylation compete or enhance the ubiquitination of those targets for which the two PTMs operate in synergy. Triplication of TTC3 may also lead to an unbalanced ubiquitination/sumoylation that selectively involves TTC3 substrates. For instance, AKT, a major target of TTC3, is also a known SUMO target, raising the possibility that enhanced AKT ubiquitination impairs its sumoylation status in DS patients. Whether other TTC3 substrates are subjected to the same regulatory mechanism is not known as the majority of TTC3 targets are not identified yet. Thus, besides assessing the level of AKT sumoylation in DS, it is of great interest to identify novel TTC3 substrates and investigate whether they are also targeted by sumoylation. A second ID form in which unbalanced ubiquitination/sumoylation could potentially play a central role is FXS. As mentioned above, novel pathologic missense point mutations in the FRM1 gene are closely located to the SUMO site $\mathrm{K} 130$ and likely interfere with FMRP sumoylation (Khayachi et al., 2018; Prieto et al., 2020). Furthermore, FMRP is also subjected to activity-dependent ubiquitination by the APC/C complex (Hou et al., 2006; Huang et al., 2015). If ubiquitin and SUMO machineries competed for the same $\mathrm{K}$ residues in FMRP sequence, defective sumoylation may promote its ubiquitination. Alternatively, if sumoylation, which is required to release FMRP from dendritic mRNA granules (Khayachi et al., 2018), is instrumental to subsequent ubiquitination, these mutations may affect FMRP degradation, resulting in reduced local translation. Finally, it is also tempting to consider this possibility in regard to the AS. Indeed, ARC, a major synaptic substrate of UBE3A, is also subjected to sumoylation (Nair et al., 2017). Together, the involvement of an unbalanced cross talk between ubiquitination and sumoylation in synaptic dysfunction of ID is an exciting hypothesis and, if confirmed by further experimental data, it would define novel principles underlying the molecular logistics of synapse physiology and the pathogenesis of a spectrum of neurodevelopmental and psychiatric disorders.

\section{Conclusions and Perspectives}

As summarized in this review, a wealth of studies clearly demonstrated pivotal roles for ubiquitination and UBLs in the assembly and refinement of neuronal circuits, maintenance of neuronal homeostasis and the emergence of complex cognitive functions. The fine spatiotemporal regulation of these PTMs is of primary importance during brain formation, a process that is characterized by intense synaptic plasticity and, on the other end, by high susceptibility to toxic insults. Therefore, genetic or environmental challenges to ubiquitination and sumoylation pathways critically contribute to the etiology of synaptopathies, including ID. Concerning neddylation, although it might be involved in ID, no evidence is currently available to support this hypothesis. The molecular mechanisms that underpin impaired ubiquitination and sumoylation in ID 
are unclear as well as a comprehensive view of neuronal ubiquitome and sumoylome is lacking. Here, we provide a few outlooks that are crucial to better understand the role of these two regulatory systems in the brain.

A major limitation to advance our knowledge on the pathophysiological role of ubiquitination and UBLs concerns the technical challenges to detect endogenous substrates. These modifications are transient and restricted to specific subcellular compartments, developmental stages, and states of neuronal activity. This results in scarcely abundant steady-state levels of modified targets. In recent years, new MS-based strategies were developed to efficiently capture ubiquitinated, sumoylated, and neddylated proteins in native tissues. For example, ubiquitomes and sumoylomes may be enriched using a novel monoclonal antibody that recognizes a di-glycine tag on $\mathrm{K}$ residues of trypsinized peptides that is present on ubiquitinated and sumoylated proteins solely ( $\mathrm{Na}$ et al., 2012; Tammsalu et al., 2015). This technique was recently combined with CRISPR-Cas9 genome editing of NEDD8 gene to reveal the neddylome in HEK cells (Vogl et al., 2020). Alternatively, the in vivo proximity-dependent biotin identification (iBiolD) approach may efficiently detect substrates of specific ubiquitin and UBL machineries (Coyaud et al., 2015; Pirone et al., 2017).

A fertile area of future research will be the investigation of environmental risk factors for ID that might affect neuronal ubiquitination and UBLs. As previously mentioned, ID-linked environmental factors comprise alcohol and drug abuse and infections during pregnancy, birth complication and severe malnutrition. For instance, prenatal exposure to one of the most commonly used anticonvulsant drugs, the valproic acid, is associated with an increased risk of autism (Christensen et al., 2013) and a few reports suggest that it may regulate the UPS (Kwon et al., 2013). Microarray transcript and proteome profiling of mouse models of fetal alcohol syndrome disorders (FASD) revealed a significant downregulation of the proteasomal function (Green et al., 2007; Mason et al., 2012). In particular, the E2 conjugating enzyme UBE2N, which is known to be critical for neurodevelopment (Muralidhar and Thomas, 1993), is among the identified proteins. Similarly, fetal cortices exposed to alcohol display an increased sumoylation of the Heat shock protein 1 (HSP1), a fundamental cellular sensor of environmental proteotoxic stress, resulting in prolonged activation of HSP1 (El Fatimy et al., 2014). The E3 SUMO ligase PIASy is upregulated in alcohol-treated cultured cells and drives the induction of autophagy (Ran et al., 2018), a well-known mechanism involved in synapse assembly and maturation (Tomoda et al., 2020). Yet, whether alcohol-dependent PIASy upregulation could contribute to synaptic dysfunction in FASD is not known. Perinatal asphyxia (PA) is an obstetric complication derived from impaired gas exchange that inevitably leads to aberrant synaptic networks and severe clinical manifestations, such as epilepsy, schizophrenia, and ID. A number of studies reported enhanced ubiquitination levels in striatal and hippocampal synapses of PA animal models (Capani et al., 2009; Saraceno et al., 2012). Furthermore, hypoxia triggers sumoylation of $\mathrm{Na}_{\mathrm{v}} 1.2$ channels (Plant et al., 2016), which provides the earliest neuronal response to hypoxia and is a major determinant of hypoxia-induced neuronal death (Weber and Taylor, 1994). Since TTX-induced inhibition of sodium currents prevents neuronal death in acute hypoxia (Taylor et al., 1995), modulation of $\mathrm{Na}_{\mathrm{v}} 1.2$ sumoylation might represent a novel target to develop neuroprotective therapies (Plant et al., 2016). Finally, nicotine administration at concentrations achieved by smokers inhibits the UPS in the prefrontal cortex of adult mice and influences synaptic plasticity by regulating the levels of multiple PSD proteins, including scaffolding molecules and receptors (Rezvani et al., 2007, 2012). However, the direct effect of smoking during pregnancy on the synaptic ubiquitome of fetal brains remains elusive. Altogether, these examples support the hypothesis that IDlinked environmental risk factors affect ubiquitin and UBLs pathways, which in turn may contribute to ID pathogenesis. As these factors typically alter multiple cellular pathways, it would be of great interest to dissect the weight of defective ubiquitination and UBLs to ID onset.

At present, no effective medical therapies are available to treat ID. Defining the roles of ubiquitination and UBL modifications and the molecular mechanisms underlying these pathways in physiological and pathologic conditions could open new venues to identify novel therapeutic strategies. Given that ubiquitination and UBLs virtually regulate all cellular processes, they are attractive drug targets. For example, compounds that modulate ubiquitination, sumoylation, and neddylation have been tested to treat cancer and other pathologies (Landré et al., 2014; Nawrocki et al., 2012; Bernstock et al., 2018). However, the majority of the molecules that are currently being tested activates or inhibits global cellular ubiquitination or UBL modifications, thus inevitably leading to relevant side effects. Therefore, the development of new compounds that precisely modulate individual components or branches of ubiquitin and UBL systems and their interaction with specific substrates is urgently needed. Finally, a better elucidation of synaptic ubiquitination and UBL pathways will be of invaluable help to move toward precision medicine.

\section{References}

Adorno M, Sikandar S, Mitra SS, Kuo A, Di Robilant BN, HaroAcosta V, Ouadah Y, Quarta M, Rodriguez J, Qian D, Reddy VM, Cheshier S, Garner CC, Clarke MF (2013) Usp16 contributes to somatic stem-cell defects in Down's syndrome. Nature 501:380384.

Ageta H, Kato A, Fukazawa Y, Inokuchi K, Sugiyama H (2001) Effects of proteasome inhibitors on the synaptic localization of Vesl-1S/ Homer-1a proteins. Brain Res Mol Brain Res 97:186-189.

Aggarwal S, Das Bhowmik A, Ramprasad VL, Murugan S, Dalal A (2016) A splice site mutation in HERC1 leads to syndromic intellectual disability with macrocephaly and facial dysmorphism: further delineation of the phenotypic spectrum. Am J Med Genet A 170:1868-1873.

Aicardi J (1998) The etiology of developmental delay. Semin Pediatr Neurol 5:15-20.

Al-Tawashi A, Jung SY, Liu D, Su B, Qin J (2012) Protein implicated in nonsyndromic mental retardation regulates protein kinase $A$ (PKA) activity. J Biol Chem 287:14644-14658. 
Anderson DD, Eom JY, Stover PJ (2012) Competition between sumoylation and ubiquitination of serine hydroxymethyltransferase 1 determines its nuclear localization and its accumulation in the nucleus. J Biol Chem 287:4790-4799.

Ang XL, Seeburg DP, Sheng M, Harper JW (2008) Regulation of postsynaptic RapGAP SPAR by polo-like kinase 2 and the $\mathrm{SCF}^{\beta-T R C P}$ ubiquitin ligase in hippocampal neurons. J Biol Chem 283:2942429432.

Antonarakis SE, Lyle R, Dermitzakis ET, Reymond A, Deutsch S (2004) Chromosome 21 and Down syndrome: from genomics to pathophysiology. Nat Rev Genet 5:725-738.

Arancibia-Cárcamo IL, Yuen EY, Muir J, Lumb MJ, Michels G, Saliba RS, Smart TG, Yan Z, Kittler JT, Moss SJ (2009) Ubiquitin-dependent lysosomal targeting of $\mathrm{GABA}_{A}$ receptors regulates neuronal inhibition. Proc Natl Acad Sci USA 106:17552-17557.

Arimura N, Menager C, Fukata Y, Kaibuchi K (2004) Role of CRMP-2 in neuronal polarity. J Neurobiol 58:34-47.

Atkin G, Moore S, Lu Y, Nelson RF, Tipper N, Rajpal G, Hunt J, Tennant W, Hell JW, Murphy GG, Paulson H (2015) Loss of F-box only protein 2 (Fbxo2) disrupts levels and localization of select NMDA receptor subunits, and promotes aberrant synaptic connectivity. J Neurosci 35:6165-6178.

Au PYB, Huang L, Broley S, Gallagher L, Creede E, Lahey D, Ordorica S, Mina K, Boycott KM, Baynam G, Dyment DA (2017) Two females with mutations in USP9X highlight the variable expressivity of the intellectual disability syndrome. Eur J Med Genet 60:359-364.

Avagliano Trezza R, Sonzogni M, Bossuyt SNV, Zampeta FI, Punt AM, van den Berg M, Rotaru DC, Koene LMC, Munshi ST, Stedehouder J, Kros JM, Williams M, Heussler H, de Vrij FMS, Mientjes EJ, van Woerden GM, Kushner SA, Distel B, Elgersma Y (2019) Loss of nuclear UBE3A causes electrophysiological and behavioral deficits in mice and is associated with Angelman syndrome. Nat Neurosci 22:1235-1247.

Bacon C, Rappold GA (2012) The distinct and overlapping phenotypic spectra of FOXP1 and FOXP2 in cognitive disorders. Hum Genet 131:1687-1698.

Bainbridge MN, Hu H, Muzny DM, Musante L, Lupski JR, Graham BH, Chen W, Gripp KW, Jenny K, Wienker TF, Yang Y, Sutton VR, Gibbs RA, Ropers HH (2013) De novo truncating mutations in ASXL3 are associated with a novel clinical phenotype with similarities to Bohring-Opitz syndrome. Genome Med 5:11.

Basel-Vanagaite L, Dallapiccola B, Ramirez-Solis R, Segref A, Thiele $H$, Edwards A, Arends MJ, Miró X, White JK, Désir J, Abramowicz M, Dentici ML, Lepri F, Hofmann K, Har-Zahav A, Ryder E, Karp NA, Estabel J, Gerdin AKB, Podrini C, et al. (2012) Deficiency for the ubiquitin ligase UBE3B in a blepharophimosis-ptosis-intellectual-disability syndrome. Am J Hum Genet 91:998-1010.

Bayraktar G, Yuanxiang P, Gomes GM, Confettura AD, Raza SA, Stork O, Tajima S, Yildirim F, Kreutz MR (2019) Synaptic control of DNA-methylation involves activity-dependent degradation of DNMT3a1 in the nucleus. bioRxiv. doi: https://doi.org/10.1101/ 602151

Bedford FK, Kittler JT, Muller E, Thomas P, Uren JM, Merlo D, Wisden W, Triller A, Smart TG, Moss SJ (2001) GABA A receptor $^{2}$ cell surface number and subunit stability are regulated by the ubiquitin-like protein Plic-1. Nat Neurosci 4:908-916.

Bernstock J, Ye D, Lee Y, Gessler F, Friedman G, Zheng W, Hallenbeck $J$ (2018) Drugging SUMOylation for neuroprotection and oncotherapy. Neural Regen Res 13:415-416.

Berto GE, lobbi C, Camera P, Scarpa E, lampietro C, Bianchi F, Gai M, Sgrò F, Cristofani F, Gärtner A, Dotti CG, Di Cunto F (2014) The DCR protein TTC3 affects differentiation and Golgi compactness in neurons through specific actin-regulating pathways. PLoS One 9:e93721.

Bianchetta MJ, Lam TKT, Jones SN, Morabito MA (2011) Cyclin-dependent kinase 5 regulates PSD-95 ubiquitination in neurons. $J$ Neurosci 31:12029-12035.

Biederer T, Südhof TC (2001) CASK and protein 4.1 support F-actin nucleation on neurexins. J Biol Chem 276:47869-47876.
Binda CS, Heimann MJ, Duda JK, Muller M, Henley JM, Wilkinson KA (2017) Analysis of protein sumoylation and SUMO pathway enzyme levels in Alzheimer's disease and down's syndrome. Opera Medica Physiol 3:19-24.

Bingol B, Schuman EM (2006) Activity-dependent dynamics and sequestration of proteasomes in dendritic spines. Nature 441:11441148.

Bingol B, Wang C-F, Arnott D, Cheng D, Peng J, Sheng M (2010) Autophosphorylated $\mathrm{CaMKII} \alpha$ acts as a scaffold to recruit proteasomes to dendritic spines. Cell 140:567-578.

Brockmann MM, Döngi M, Einsfelder U, Körber N, Refojo D, Stein V (2019) Neddylation regulates excitatory synaptic transmission and plasticity. Sci Rep 9:1-10.

Budny B, Badura-Stronka M, Materna-Kiryluk A, Tzschach A, Raynaud M, Latos-Bielenska A, Ropers H (2010) Novel missense mutations in the ubiquitination-related gene UBE2A cause a recognizable X-linked mental retardation syndrome. Clin Genet 77:541-551.

Buiting K, Williams C, Horsthemke B (2016) Angelman syndrome insights into a rare neurogenetic disorder. Nat Rev Neurol 12:584593.

Burbea M, Dreier L, Dittman JS, Grunwald ME, Kaplan JM (2002) Ubiquitin and AP180 regulate the abundance of GLR-1 glutamate receptors at postsynaptic elements in C. elegans. Neuron 35:107120.

Burette AC, Judson MC, Li AN, Chang EF, Seeley WW, Philpot BD, Weinberg RJ (2018) Subcellular organization of UBE3A in human cerebral cortex. Mol Autism 9:54.

Bürkle A (2001) Posttranslational modification. In: Encyclopedia of Genetics. Amsterdam: Elsevier.

Campbell MK, Sheng M (2018) USP8 deubiquitinates SHANK3 to control synapse density and SHANK3 activity-dependent protein levels. J Neurosci 38:5289-5301.

Capani F, Saraceno GE, Botti V, Aon-Bertolino L, Madureira de Oliveira D, Barreto G, Galeano P, Giraldez-Alvarez LD, Coirini H (2009) Protein ubiquitination in postsynaptic densities after hypoxia in rat neostriatum is blocked by hypothermia. Exp Neurol 219:404-413.

Carapito R, Ivanova EL, Morlon A, Meng L, Molitor A, Erdmann E, Kieffer B, Pichot A, Naegely L, Kolmer A, Paul N, Hanauer A, Tran Mau-Them F, Jean-Marçais N, Hiatt SM, Cooper GM, Tvrdik T, Muir AM, Dimartino C, Chopra M, et al. (2019) ZMIZ1 variants cause a syndromic neurodevelopmental disorder. Am J Hum Genet 104:319-330.

Castillo PE, Schoch S, Schmitz F, Südhof TC, Malenka RC (2002) $\operatorname{RIM} 1 \alpha$ is required for presynaptic long-term potentiation. Nature 415:327-330.

Castillo PE, Younts TJ, Chávez AE, Hashimotodani Y (2012) Endocannabinoid signaling and synaptic function. Neuron 76:7081.

Chamberlain SEL, González-González IM, Wilkinson KA, Konopacki FA, Kantamneni S, Henley JM, Mellor JR (2012) SUMOylation and phosphorylation of GluK2 regulate kainate receptor trafficking and synaptic plasticity. Nat Neurosci 15:845-852.

Chao HW, Hong CJ, Huang TN, Lin YL, Hsueh YP (2008) SUMOylation of the MAGUK protein CASK regulates dendritic spinogenesis. J Cell Biol 182:141-155.

Cheng J, Kang X, Zhang S, Yeh ETH (2007) SUMO-specific protease 1 is essential for stabilization of $\mathrm{HIF}_{1} \alpha$ during hypoxia. Cell 131:584-595.

Cheng J, Huang M, Zhu Y, Xin YJ, Zhao YK, Huang J, Yu JX, Zhou WH, Qiu Z (2014) SUMOylation of MeCP2 is essential for transcriptional repression and hippocampal synapse development. J Neurochem 128:798-806.

Chin LS, Vavalle JP, Li L (2002) Staring, a novel Elll ubiquitin-protein ligase that targets syntaxin 1 for degradation. J Biol Chem 277:35071-35079.

Choi JH, Park JY, Park SP, Lee H, Han S, Park KH, Suh YH (2016) Regulation of mGluR7 trafficking by SUMOylation in neurons. Neuropharmacology 102:229-235. 
Choquet D, Triller A (2013) The dynamic synapse. Neuron 80:691703.

Christensen J, Grønborg TK, Sørensen MJ, Schendel D, Parner ET, Pedersen LH, Vestergaard M (2013) Prenatal valproate exposure and risk of autism spectrum disorders and childhood autism. JAMA 309:1696-1703.

Clayton-Smith J, Laan L (2003) Angelman syndrome: a review of the clinical and genetic aspects. J Med Genet 40:87-95.

Coba MP (2019) Regulatory mechanisms in postsynaptic phosphorylation networks. Curr Opin Struct Biol 54:86-94.

Colledge M, Snyder EM, Crozier RA, Soderling JA, Jin Y, Langeberg LK, Lu H, Bear MF, Scott JD (2003) Ubiquitination regulates PSD95 degradation and AMPA receptor surface expression. Neuron 40:595-607.

Collins SC, Bray SM, Suhl JA, Cutler DJ, Coffee B, Zwick ME, Warren ST (2010) Identification of novel FMR1 variants by massively parallel sequencing in developmentally delayed males. Am J Med Genet A 152A:2512-2520.

Colnaghi L, Russo L, Natale C, Restelli E, Cagnotto A, Salmona M, Chiesa R, Fioriti L (2019) Super resolution microscopy of SUMO proteins in neurons. Front Cell Neurosci 13:1-12.

Coultrap SJ, Bayer KU (2012) CaMKII regulation in information processing and storage. Trends Neurosci 35:607-618.

Coyaud E, Mis M, Laurent EMN, Dunham WH, Couzens AL, Robitaille M, Gingras A-C, Angers S, Raught B (2015) BiolD-based identification of Skp cullin F-box (SCF) $\beta$-TrCP1/2 Elll ligase substrates. Mol Cell Proteomics 14:1781-1795.

Craig TJ, Henley JM (2012) SUMOylation, Arc and the regulation homeostatic synaptic scaling. Commun Integr Biol 5:634-636.

Craig TJ, Jaafari N, Petrovic MM, Jacobs SC, Rubin PP, Mellor JR, Henley JM (2012) Homeostatic synaptic scaling is regulated by protein SUMOylation. J Biol Chem 287:22781-22788.

Craig TJ, Anderson D, Evans AJ, Girach F, Henley JM (2015) SUMOylation of Syntaxin1A regulates presynaptic endocytosis. Sci Rep 5:17669.

Daniel JA, Cooper BH, Palvimo JJ, Zhang FP, Brose N, Tirard M (2017) Analysis of SUMO1-conjugation at synapses. Elife 6: e26338.

Daniel JA, Cooper BH, Palvimo JJ, Zhang F-P, Brose N, Tirard M (2018) Response: commentary: analysis of SUMO1-conjugation at synapses. Front Cell Neurosci 12:1-6.

De Rubeis S, He X, Goldberg AP, Poultney CS, Samocha K, Ercument Cicek A, Kou Y, Liu L, Fromer M, Walker S, Singh T, Klei L, Kosmicki J, Fu SC, Aleksic B, Biscaldi M, Bolton PF, Brownfeld JM, Cai J, Campbell NG, et al. (2014) Synaptic, transcriptional and chromatin genes disrupted in autism. Nature 515:209-215.

DeFelipe $J$ (2011) The evolution of the brain, the human nature of cortical circuits, and intellectual creativity. Front Neuroanat 5:29.

Diaz J, Scheiner C, Leon E (2018) Presentation of a recurrent FMR1 missense mutation (R138Q) in an affected female. TRD 3:139-144.

Diering GH, Huganir RL (2018) The AMPA receptor code of synaptic plasticity. Neuron 100:314-329.

Dindot SV, Antalffy BA, Bhattacharjee MB, Beaudet AL (2008) The Angelman syndrome ubiquitin ligase localizes to the synapse and nucleus, and maternal deficiency results in abnormal dendritic spine morphology. Hum Mol Genet 17:111-118.

Dreier L, Burbea M, Kaplan JM (2005) LIN-23-mediated degradation of $\beta$-catenin regulates the abundance of GLR-1 glutamate receptors in the ventral nerve cord of $C$. elegans. Neuron 46:51-64.

Dustrude ET, Wilson SM, Ju W, Xiao Y, Khanna R (2013) CRMP2 protein SUMOylation modulates NaV1.7 channel trafficking. J Biol Chem 288:24316-24331.

Dustrude ET, Moutal A, Yang X, Wang Y, Khanna M, Khanna R (2016) Hierarchical CRMP2 posttranslational modifications control NaV1.7 function. Proc Natl Acad Sci USA 113:E8443-E8452.

Dustrude ET, Perez-Miller S, François-Moutal L, Moutal A, Khanna M, Khanna R (2017) A single structurally conserved SUMOylation site in CRMP2 controls NaV1.7 function. Channels (Austin) $11: 316-328$
Dütting E, Schröder-Kress N, Sticht H, Enz R (2011) SUMO Elll ligases are expressed in the retina and regulate SUMOylation of the metabotropic glutamate receptor 8b. Biochem J 435:365-371.

Ehlers MD (2003) Activity level controls postsynaptic composition and signaling via the ubiquitin-proteasome system. Nat Neurosci 6:231-242.

Ehrlich I, Klein M, Rumpel S, Malinow R (2007) PSD-95 is required for activity-driven synapse stabilization. Proc Natl Acad Sci USA 104:4176-4181.

El Fatimy R, Miozzo F, Mouël A, Abane R, Schwendimann L, SabéranDjoneidi D, Thonel A, Massaoudi I, Paslaru L, Hashimoto -Torii K, Christians E, Rakic P, Gressens P, Mezger V (2014) Heat shock factor 2 is a stress-responsive mediator of neuronal migration defects in models of fetal alcohol syndrome. EMBO Mol Med 6:1043-1061.

Emtage L, Chang H, Tiver R, Rongo C (2009) MAGI-1 modulates AMPA receptor synaptic localization and behavioral plasticity in response to prior experience. PLoS One 4:e4613.

Enchev RI, Schulman BA, Peter M (2015) Protein neddylation: beyond cullin-RING ligases. Nat Rev Mol Cell Biol 16:30-44.

Estruch SB, Graham SA, Deriziotis P, Fisher SE (2016) The languagerelated transcription factor FOXP2 is post-translationally modified with small ubiquitin-like modifiers. Sci Rep 6:20911.

Falik Zaccai TC, Savitzki D, Zivony-Elboum Y, Vilboux T, Fitts EC, Shoval Y, Kalfon L, Samra N, Keren Z, Gross B, Chasnyk N, Straussberg R, Mullikin JC, Teer JK, Geiger D, Kornitzer D, Bitterman-Deutsch O, Samson AO, Wakamiya M, Peterson JW, et al. (2017) Phospholipase A 2-activating protein is associated with a novel form of leukoencephalopathy. Brain 140:370-386.

Feligioni M, Nishimune A, Henley JM (2009) Protein SUMOylation modulates calcium influx and glutamate release from presynaptic terminals. Eur J Neurosci 29:1348-1356.

Flotho A, Melchior F (2013) Sumoylation: a regulatory protein modification in health and disease. Annu Rev Biochem 82:357-385.

Froyen G, Corbett M, Vandewalle J, Jarvela I, Lawrence O, Meldrum C, Bauters M, Govaerts K, Vandeleur L, Van Esch H, Chelly J, Sanlaville D, van Bokhoven $\mathrm{H}$, Ropers $\mathrm{HH}$, Laumonnier F, Ranieri E, Schwartz CE, Abidi F, Tarpey PS, Futreal PA, et al. (2008) Submicroscopic duplications of the hydroxysteroid dehydrogenase HSD17B10 and the EIII ubiquitin ligase HUWE1 are associated with mental retardation. Am J Hum Genet 82:432-443.

Gardiner K (2006) Transcriptional dysregulation in Down syndrome: predictions for altered protein complex stoichiometries and posttranslational modifications, and consequences for learning/behavior genes ELK, CREB, and the estrogen and glucocorticoid receptors. Behav Genet 36:439-453.

Gascón S, García-Gallo M, Renart J, Díaz-Guerra M (2007) Endoplasmic reticulum-associated degradation of the NR1 but not the NR2 subunits of the N-methyl-D-aspartate receptor induced by inhibition of the $\mathrm{N}$-glycosylation in cortical neurons. J Neurosci Res 85:1713-1723.

Gautam V, Trinidad JC, Rimerman RA, Costa BM, Burlingame AL, Monaghan DT (2013) Nedd4 is a specific Elll ubiquitin ligase for the NMDA receptor subunit GluN2D. Neuropharmacology 74:96107.

Geetha TS, Michealraj KA, Kabra M, Kaur G, Juyal RC, Thelma BK (2014) Targeted deep resequencing identifies MID2 mutation for $\mathrm{X}$-linked intellectual disability with varied disease severity in a large kindred from India. Hum Mutat 35:41-44.

George AJ, Hoffiz YC, Charles AJ, Zhu Y, Mabb AM (2018) A comprehensive atlas of Elll ubiquitin ligase mutations in neurological disorders. Front Genet 9:1-17.

Geschwind DH, Rakic P (2013) Cortical evolution: judge the brain by its cover. Neuron 80:633-647.

Ghosh H, Auguadri L, Battaglia S, Simone Thirouin Z, Zemoura K, Messner S, Acuña MA, Wildner $H$, Yévenes GE, Dieter A, Kawasaki H, O. Hottiger M, Zeilhofer HU, Fritschy J-M, Tyagarajan SK (2016) Several posttranslational modifications act in concert to regulate gephyrin scaffolding and GABAergic transmission. Nat Commun 7:13365. 
Girach F, Craig TJ, Rocca DL, Henley JM (2013) RIM1 $\alpha$ SUMOylation is required for fast synaptic vesicle exocytosis. Cell Rep 5:1294-1301.

Gowran A, Murphy CE, Campbell VA (2009) Delta(9)-tetrahydrocannabinol regulates the p53 post-translational modifiers murine double minute 2 and the small ubiquitin modifier protein in the rat brain. FEBS Lett 583:3412-3418.

Green ML, Singh AV, Zhang Y, Nemeth KA, Sulik KK, Knudsen TB (2007) Reprogramming of genetic networks during initiation of the fetal alcohol syndrome. Dev Dyn 236:613-631.

Greer PL, Hanayama R, Bloodgood BL, Mardinly AR, Lipton DM, Flavell SW, Kim TK, Griffith EC, Waldon Z, Maehr R, Ploegh HL, Chowdhury S, Worley PF, Steen J, Greenberg ME (2010) The Angelman syndrome protein Ube3A regulates synapse development by ubiquitinating arc. Cell 140:704-716.

Greger IH, Watson JF, Cull-Candy SG (2017) Structural and functional architecture of AMPA-type glutamate receptors and their auxiliary proteins. Neuron 94:713-730.

Grégoire S, Tremblay AM, Xiao L, Yang Q, Ma K, Nie J, Mao Z, Wu Z, Giguère V, Yang XJ (2006) Control of MEF2 transcriptional activity by coordinated phosphorylation and sumoylation. $\mathrm{J}$ Biol Chem 281:4423-4433.

Gulia R, Sharma R, Bhattacharyya S (2017) A critical role for ubiquitination in the endocytosis of glutamate receptors. J Biol Chem 292:1426-1437.

Guy J, Cheval H, Selfridge J, Bird A (2011) The role of MeCP2 in the brain. Annu Rev Cell Dev Biol 27:631-652.

Hall EA, Nahorski MS, Murray LM, Shaheen R, Perkins E, Dissanayake KN, Kristaryanto Y, Jones RA, Vogt J, Rivagorda M, Handley MT, Mali GR, Quidwai T, Soares DC, Keighren MA, McKie L, Mort RL, Gammoh N, Garcia-Munoz A, Davey T, et al. (2017) PLAA mutations cause a lethal infantile epileptic encephalopathy by disrupting ubiquitin-mediated endolysosomal degradation of synaptic proteins. Am J Hum Genet 100:706-724.

Halvardson J, Zhao JJ, Zaghlool A, Wentzel C, Georgii-Hemming P, Månsson E, Sävmarker HE, Brandberg G, Zander CS, Thuresson AC, Feuk L (2016) Mutations in HECW2 are associated with intellectual disability and epilepsy. J Med Genet 53:697-704.

Hasegawa Y, Yoshida D, Nakamura Y, Sakakibara SI (2014) Spatiotemporal distribution of SUMOylation components during mouse brain development. J Comp Neurol 522:3020-3036.

Hegde AN, DiAntonio A (2002) Ubiquitin and the synapse. Nat Rev Neurosci 3:854-861.

Henderson NT, Dalva MB (2018) EphBs and ephrin-Bs: trans-synaptic organizers of synapse development and function. Mol Cell Neurosci 91:108-121.

Henley JM, Carmichael RE, Wilkinson KA (2018) Extranuclear SUMOylation in neurons. Trends Neurosci 41:198-210.

Hensch TK (2005) Critical period plasticity in local cortical circuits. Nat Rev Neurosci 6:877-888.

Hers I, Vincent EE, Tavaré JM (2011) Akt signalling in health and disease. Cell Signal 23:1515-1527.

Hou L, Antion MD, Hu D, Spencer CM, Paylor R, Klann E (2006) Dynamic translational and proteasomal regulation of fragile $\mathrm{X}$ mental retardation protein controls mGluR-dependent long-term depression. Neuron 51:441-454.

Hsu WL, Ma YL, Liu YC, Tai DJC, Lee EHY (2020) Restoring Wnt6 signaling ameliorates behavioral deficits in MeCP2 T158A mouse model of Rett syndrome. Sci Rep 10:1074.

Huang D, Liu H, Zhu A, Zhou Y, Li Y (2020) Forebrain excitatory neuron-specific SENP2 knockout mouse displays hyperactivity, impaired learning and memory, and anxiolytic-like behavior. Mol Brain 13:59.

Huang J, Ikeuchi Y, Malumbres M, Bonni A (2015) A Cdh1-APC/ FMRP ubiquitin signaling link drives mGluR-dependent synaptic plasticity in the mammalian brain. Neuron 86:726-739.

Huang TT, Wuerzberger-Davis SM, Wu Z-H, Miyamoto S (2003) Sequential modification of NEMO/IKKgamma by SUMO-1 and ubiquitin mediates NF-kappaB activation by genotoxic stress. Cell 115:565-576.
Huganir RL, Nicoll RA (2013) AMPARs and synaptic plasticity: the last 25 years. Neuron 80:704-717.

Hung AY, Sung CC, Brito IL, Sheng M (2010) Degradation of postsynaptic scaffold GKAP and regulation of dendritic spine morphology by the TRIM3 ubiquitin ligase in rat hippocampal neurons. PLoS One 5:e9842.

Huo Y, Khatri N, Hou Q, Gilbert J, Wang G, Man HY (2015) The deubiquitinating enzyme USP46 regulates AMPA receptor ubiquitination and trafficking. J Neurochem 134:1067-1080.

Ilyas M, Mir A, Efthymiou S, Houlden H (2020) The genetics of intellectual disability: advancing technology and gene editing. F1000Res 9:22.

Jaafari N, Konopacki FA, Owen TF, Kantamneni S, Rubin P, Craig TJ, Wilkinson KA, Henley JM (2013) SUMOylation is required for glycine-induced increases in AMPA receptor surface expression (ChemLTP) in hippocampal neurons. PLoS One 8:e52345.

Jarome TJ, Helmstetter FJ (2013) The ubiquitin-proteasome system as a critical regulator of synaptic plasticity and long-term memory formation. Neurobiol Learn Mem 105:107-116.

Jeong J, Paskus JD, Roche KW (2017) Posttranslational modifications of neuroligins regulate neuronal and glial signaling. Curr Opin Neurobiol 45:130-138.

Jin $H$, Chiou TT, Serwanski DR, Miralles CP, Pinal N, De Blas AL (2014) Ring finger protein 34 (RNF34) interacts with and promotes $\gamma$-aminobutyric acid type-a receptor degradation via ubiquitination of the $\gamma 2$ subunit. J Biol Chem 289:29420-29436.

Josa-Prado F, Luo J, Rubin P, Henley JM, Wilkinson KA (2019) Developmental profiles of SUMOylation pathway proteins in rat cerebrum and cerebellum. PLoS One 14:e0212857.

Ju W, Li Q, Wilson SM, Brittain JM, Meroueh L, Khanna R (2013) SUMOylation alters CRMP2 regulation of calcium influx in sensory neurons. Channels (Austin) 7:153-159.

Judson MC, Wallace ML, Sidorov MS, Burette AC, Gu B, van Woerden GM, King IF, Han JE, Zylka MJ, Elgersma Y, Weinberg RJ, Philpot BD (2016) GABAergic neuron-specific loss of Ube3a causes Angelman syndrome-like EEG abnormalities and enhances seizure susceptibility. Neuron 90:56-69.

Juo P, Kaplan JM (2004) The anaphase-promoting complex regulates the abundance of GLR-1 glutamate receptors in the ventral nerve cord of $C$. elegans. Curr Biol 14:2057-2062.

Jurd R, Thornton C, Wang J, Luong K, Phamluong K, Kharazia V, Gibb SL, Ron D (2008) Mind Bomb-2 is an EIII ligase that ubiquitinates the N-methyl-d-aspartate receptor NR2B subunit in a phosphorylation-dependent manner. J Biol Chem 283:301-310.

Kalchman MA, Graham RK, Xia G, Koide HB, Hodgson JG, Graham KC, Goldberg YP, Gietz RD, Pickart CM, Hayden MR (1996) Huntingtin is ubiquitinated and interacts with a specific ubiquitinconjugating enzyme. J Biol Chem 271:19385-19394.

Kang J, Gocke CB, Yu H (2006) Phosphorylation-facilitated sumoylation of MEF2C negatively regulates its transcriptional activity. BMC Biochem 7:5.

Kato A, Rouach N, Nicoll RA, Bredt DS (2005) Activity-dependent NMDA receptor degradation mediated by retrotranslocation and ubiquitination. Proc Natl Acad Sci USA 102:5600-5605.

Khayachi A, Gwizdek C, Poupon G, Alcor D, Chafai M, Cassé F, Maurin T, Prieto M, Folci A, De Graeve F, Castagnola S, Gautier R, Schorova L, Loriol C, Pronot M, Besse F, Brau F, Deval E, Bardoni B, Martin S (2018) Sumoylation regulates FMRP-mediated dendritic spine elimination and maturation. Nat Commun 9:757.

Kim H, Kunz PA, Mooney R, Philpot BD, Smith SL (2016) Maternal loss of Ube3a impairs experience-driven dendritic spine maintenance in the developing visual cortex. J Neurosci 36:4888-4894.

Kleijnen MF, Shih AH, Zhou P, Kumar S, Soccio RE, Kedersha NL, Gill G, Howley PM (2000) The hPLIC proteins may provide a link between the ubiquitination machinery and the proteasome. Mol Cell 6:409-419.

Ko SJ, Isozaki K, Kim I, Lee JH, Cho HJ, Sohn SY, Oh SR, Park S, Kim DG, Kim CH, Roche KW (2012) PKC phosphorylation regulates mGluR5 trafficking by enhancing binding of Siah-1A. J Neurosci 32:16391-16401. 
Komander D, Rape M (2012) The ubiquitin code. Annu Rev Biochem 81:203-229.

Konopacki FA, Jaafari N, Rocca DL, Wilkinson KA, Chamberlain S, Rubin P, Kantamneni S, Mellor JR, Henley JM (2011) Agonist-induced PKC phosphorylation regulates GluK2 SUMOylation and kainate receptor endocytosis. Proc Natl Acad Sci USA 108:1977219777.

Kowalski JR, Juo P (2012) The role of deubiquitinating enzymes in synaptic function and nervous system diseases. Neural Plast 2012:892749-892713.

Kowalski JR, Dube H, Touroutine D, Rush KM, Goodwin PR, Carozza M, Didier Z, Francis MM, Juo P (2014) The anaphase-promoting complex (APC) ubiquitin ligase regulates GABA transmission at the $C$. elegans neuromuscular junction. Mol Cell Neurosci 58:6275.

Kuczera T, Stilling RM, Hsia H-E, Bahari-Javan S, Irniger S, Nasmyth $\mathrm{K}$, Sananbenesi F, Fischer A (2010) The anaphase promoting complex is required for memory function in mice. Learn Mem 18:4957.

Kühnle S, Mothes B, Matentzoglu K, Scheffner M (2013) Role of the ubiquitin ligase E6AP/UBE3A in controlling levels of the synaptic protein Arc. Proc Natl Acad Sci USA 110:8888-8893.

Kumar S, Tomooka Y, Noda M (1992) Identification of a set of genes with developmentally down-regulated expression in the mouse brain. Biochem Biophys Res Commun 185:1155-1161.

Kwon KJ, Kim JN, Kim MK, Kim SY, Cho KS, Jeon SJ, Kim HY, Ryu JH, Han S-Y, Cheong JH, Ignarro LJ, Han S-H, Shin CY (2013) Neuroprotective effects of valproic acid against hemin toxicity: possible involvement of the down-regulation of heme oxygenase1 by regulating ubiquitin-proteasomal pathway. Neurochem Int 62:240-250.

Landré V, Rotblat B, Melino S, Bernassola F, Melino G (2014) Screening for Elll-ubiquitin ligase inhibitors: challenges and opportunities. Oncotarget 5:7988-8013.

Lappe-Siefke C, Loebrich S, Hevers W, Waidmann OB, Schweizer M, Fehr S, Fritschy J-M, Dikic I, Eilers J, Wilson SM, Kneussel M (2009) The ataxia (axJ) mutation causes abnormal GABAA receptor turnover in mice. PLoS Genet 5:e1000631.

Leal $T$, Andrieux J, Duban-Bedu B, Bouquillon S, Brevière GM, Delobel B (2009) Array-CGH detection of a de novo $0.8 \mathrm{Mb}$ deletion in 19q13.32 associated with mental retardation, cardiac malformation, cleft lip and palate, hearing loss and multiple dysmorphic features. Eur J Med Genet 52:62-66.

Lee L, Dale E, Staniszewski A, Zhang H, Saeed F, Sakurai M, Fa' M, Orozco I, Michelassi F, Akpan N, Lehrer H, Arancio O (2014) Regulation of synaptic plasticity and cognition by SUMO in normal physiology and Alzheimer's disease. Sci Rep 4:7190.

Lee SH, Choi JH, Lee N, Lee HR, Kim JI, Yu NK, Choi SL, Lee SH, Kim H, Kaang BK (2008) Synaptic protein degradation underlies destabilization of retrieved fear memory. Science 319:1253-1256.

Lee S, Park S, Lee H, Han S, Song J, Han D, Suh YH (2019) Nedd4 EIII ligase and beta-arrestins regulate ubiquitination, trafficking, and stability of the mGlu7 receptor. Elife 8:e44502.

Li M, Shin Y-H, Hou L, Huang X, Wei Z, Klann E, Zhang P (2008) The adaptor protein of the anaphase promoting complex Cdh1 is essential in maintaining replicative lifespan and in learning and memory. Nat Cell Biol 10:1083-1089.

Loriol C, Parisot J, Poupon G, Gwizdek C, Martin S (2012) Developmental regulation and spatiotemporal redistribution of the sumoylation machinery in the rat central nervous system. PLoS One 7:e33757.

Loriol C, Khayachi A, Poupon G, Gwizdek C, Martin S (2013) Activitydependent regulation of the sumoylation machinery in rat hippocampal neurons. Biol Cell 105:30-45.

Loriol C, Cassé F, Khayachi A, Poupon G, Chafai M, Deval E, Gwizdek C, Martin S (2014) mGlu5 receptors regulate synaptic sumoylation via a transient PKC-dependent diffusional trapping of Ubc9 into spines. Nat Commun 5:5113.

Luo HB, Xia YY, Shu XJ, Liu ZC, Feng Y, Liu XH, Yu G, Yin G, Xiong YS, Zeng K, Jiang J, Ye K, Wang XC, Wang JZ (2014)
SUMOylation at K340 inhibits tau degradation through deregulating its phosphorylation and ubiquitination. Proc Natl Acad Sci USA 111:16586-16591.

Luscher B, Fuchs T, Kilpatrick CL (2011) GABAA receptor traffickingmediated plasticity of inhibitory synapses. Neuron 70:385-409.

Lussier MP, Nasu-Nishimura Y, Roche KW (2011) Activity-dependent ubiquitination of the AMPA receptor subunit GluA2. J Neurosci 31:3077-3081.

Lussier MP, Herring BE, Nasu-Nishimura Y, Neutzner A, Karbowski M, Youle RJ, Nicoll RA, Roche KW (2012) Ubiquitin ligase RNF167 regulates AMPA receptor-mediated synaptic transmission. Proc Natl Acad Sci USA 109:19426-19431.

Mabb AM, Ehlers MD (2010) Ubiquitination in postsynaptic function and plasticity. Annu Rev Cell Dev Biol 26:179-210.

Mabb AM, Judson MC, Zylka MJ, Philpot BD (2011) Angelman syndrome: insights into genomic imprinting and neurodevelopmental phenotypes. Trends Neurosci 34:293-303.

Mabb AM, Je HS, Wall MJ, Robinson CG, Larsen RS, Qiang Y, Corrêa SAL, Ehlers MD (2014) Triad3A regulates synaptic strength by ubiquitination of arc. Neuron 82:1299-1316.

Mahajan R, Delphin C, Guan T, Gerace L, Melchior F (1997) A small ubiquitin-related polypeptide involved in targeting RanGAP1 to nuclear pore complex protein RanBP2. Cell 88:97-107.

Manzini MC, Xiong L, Shaheen R, Tambunan DE, Di Costanzo S, Mitisalis V, Tischfield DJ, Cinquino A, Ghaziuddin M, Christian M, Jiang Q, Laurent S, Nanjiani ZA, Rasheed S, Hill RS, Lizarraga SB, Gleason D, Sabbagh D, Salih MA, Alkuraya FS, et al. (2014) CC2D1A regulates human intellectual and social function as well as NF- $\kappa$ B signaling homeostasis. Cell Rep 8:647-655.

Mao SC, Lin HC, Gean PW (2008) Augmentation of fear extinction by $\mathrm{D}$-cycloserine is blocked by proteasome inhibitors. Neuropsychopharmacology 33:3085-3095.

Maraschi A, Ciammola A, Folci A, Sassone F, Ronzitti G, Cappelletti G, Silani V, Sato S, Hattori N, Mazzanti M, Chieregatti E, Mulle C, Passafaro M, Sassone J (2014) Parkin regulates kainate receptors by interacting with the GluK2 subunit. Nat Commun 5:5182.

Margolis SS, Salogiannis J, Lipton DM, Mandel-Brehm C, Wills ZP, Mardinly AR, Hu L, Greer PL, Bikoff JB, Ho H-YH, Soskis MJ, Sahin M, Greenberg ME (2010) EphB-mediated degradation of the RhoA GEF Ephexin5 relieves a developmental brake on excitatory synapse formation. Cell 143:442-455.

Margolis SS, Sell GL, Zbinden MA, Bird LM (2015) Angelman syndrome. Neurotherapeutics 12:641-650.

Martin S, Nishimune A, Mellor JR, Henley JM (2007) SUMOylation regulates kainate-receptor-mediated synaptic transmission. Nature 447:321-325.

Mason S, Anthony B, Lai X, Ringham HN, Wang M, Witzmann FA, You J-S, Zhou FC (2012) Ethanol exposure alters protein expression in a mouse model of fetal alcohol spectrum disorders. Int $\mathrm{J}$ Proteomics 2012:1-10.

Matsuzaki S, Lee L, Knock E, Srikumar T, Sakurai M, Hazrati L-N, Katayama T, Staniszewski A, Raught B, Arancio O, Fraser PE (2015) SUMO1 affects synaptic function, spine density and memory. Sci Rep 5:10730.

Matunis MJ, Coutavas E, Blobel G (1996) A novel ubiquitin-like modification modulates the partitioning of the Ran-GTPase-activating protein RanGAP1 between the cytosol and the nuclear pore complex. J Cell Biol 135:1457-1470.

Meredith LJ, Wang C-M, Nascimento L, Liu R, Wang L, Yang W-H (2016) The key regulator for language and speech development, FOXP2, is a novel substrate for SUMOylation. J Cell Biochem 117:426-438.

Miao S, Chen R, Ye J, Tan GH, Li S, Zhang J, Jiang Yh, Xiong ZQ (2013) The Angelman syndrome protein Ube3a is required for polarized dendrite morphogenesis in pyramidal neurons. J Neurosci 33:327-333.

Micale L, Fusco C, Augello B, Napolitano LMR, Dermitzakis ET, Meroni G, Merla G, Reymond A (2008) Williams-Beuren syndrome TRIM50 encodes an ElII ubiquitin ligase. Eur J Hum Genet 16:1038-1049. 
Moortgat S, Berland S, Aukrust I, Maystadt I, Baker L, Benoit V, Caro-Llopis A, Cooper NS, Debray FG, Faivre L, Gardeitchik T, Haukanes BI, Houge G, Kivuva E, Martinez F, Mehta SG, Nassogne MC, Powell-Hamilton N, Pfundt R, Rosello M, et al. (2018) HUWE1 variants cause dominant X-linked intellectual disability: a clinical study of 21 patients. Eur J Hum Genet 26:64-74.

Moriyoshi K, lijima K, Fujii H, Ito H, Cho Y, Nakanishi S (2004) Seven in absentia homolog $1 \mathrm{~A}$ mediates ubiquitination and degradation of group 1 metabotropic glutamate receptors. Proc Natl Acad Sci USA 101:8614-8619.

Muralidhar MG, Thomas JB (1993) The Drosophila bendless gene encodes a neural protein related to ubiquitin-conjugating enzymes. Neuron 11:253-266.

$\mathrm{Na}$ CH, Jones DR, Yang Y, Wang X, Xu Y, Peng J (2012) Synaptic protein ubiquitination in rat brain revealed by antibody-based ubiquitome analysis. J Proteome Res 11:4722-4732.

Nair RR, Patil S, Tiron A, Kanhema T, Panja D, Schiro L, Parobczak K, Wilczynski G, Bramham CR (2017) Dynamic Arc SUMOylation and selective interaction with F-actin-binding protein Drebrin A in LTP consolidation in vivo. Front Synaptic Neurosci 9:1-14.

Nascimento RMP, Otto PA, de Brouwer APM, Vianna-Morgante AM (2006) UBE2A, which encodes a ubiquitin-conjugating enzyme, is mutated in a novel $\mathrm{X}$-linked mental retardation syndrome. Am J Hum Genet 79:549-555.

Nawaz Z, Lonard DM, Smith CL, Lev-Lehman E, Tsai SY, Tsai MJ, O'Malley BW (1999) The Angelman syndrome-associated protein, EVI-AP, is a coactivator for the nuclear hormone receptor superfamily. Mol Cell Biol 19:1182-1189.

Nawrocki ST, Griffin P, Kelly KR, Carew JS (2012) MLN4924: a novel first-in-class inhibitor of NEDD8-activating enzyme for cancer therapy. Expert Opin Investig Drugs 21:1563-1573.

Necchi D, Lomoio S, Scherini E (2011) Dysfunction of the ubiquitinproteasome system in the cerebellum of aging Ts65Dn mice. Exp Neurol 232:114-118.

Nelson RF, Glenn KA, Miller VM, Wen H, Paulson HL (2006) A novel route for F-box protein-mediated ubiquitination links CHIP to glycoprotein quality control. J Biol Chem 281:20242-20251.

Ngo-Anh TJ, Bloodgood BL, Lin M, Sabatini BL, Maylie J, Adelman JP (2005) SK channels and NMDA receptors form a Ca2+-mediated feedback loop in dendritic spines. Nat Neurosci 8:642-649.

Nguyen LS, Schneider T, Rio M, Moutton S, Siquier-Pernet K, Verny F, Boddaert N, Desguerre I, Munich A, Rosa JL, Cormier-Daire V, Colleaux $L$ (2016) A nonsense variant in HERC1 is associated with intellectual disability, megalencephaly, thick corpus callosum and cerebellar atrophy. Eur J Hum Genet 24:455-458.

Niswender CM, Conn PJ (2010) Metabotropic glutamate receptors: physiology, pharmacology, and disease. Annu Rev Pharmacol Toxicol 50:295-322.

Oaks AW, Zamarbide M, Tambunan DE, Santini E, Di Costanzo S, Pond HL, Johnson MW, Lin J, Gonzalez DM, Boehler JF, Wu GK, Klann E, Walsh CA, Manzini MC (2017) Cc2d1a loss of function disrupts functional and morphological development in forebrain neurons leading to cognitive and social deficits. Cereb Cortex 27:1670-1685.

Ortega-Recalde O, Beltrán OI, Gálvez JM, Palma-Montero A, Restrepo CM, Mateus HE, Laissue P (2015) Biallelic HERC1 mutations in a syndromic form of overgrowth and intellectual disability. Clin Genet 88:e1-e3.

Ou Z, Jarmuz M, Sparagana SP, Michaud J, Décarie JC, Yatsenko SA, Nowakowska B, Furman P, Shaw CA, Shaffer LG, Lupski JR, Chinault AC, Cheung SW, Stankiewicz P (2006) Evidence for involvement of TRE-2 (USP6) oncogene, low-copy repeat and acrocentric heterochromatin in two families with chromosomal translocations. Hum Genet 120:227-237.

Pak DTS, Sheng M (2003) Targeted protein degradation and synapse remodeling by an inducible protein kinase. Science 302:13681373.

Pak DTS, Yang S, Rudolph-Correia S, Kim E, Sheng M (2001) Regulation of dendritic spine morphology by SPAR, a PSD-95-associated RapGAP. Neuron 31:289-303.
Paoletti P, Bellone C, Zhou Q (2013) NMDA receptor subunit diversity: impact on receptor properties, synaptic plasticity and disease. Nat Rev Neurosci 14:383-400.

Picker JD, Walsh CA (2013) New innovations: therapeutic opportunities for intellectual disabilities. Ann Neurol 74:382-390.

Pignatelli M, Piccinin S, Molinaro G, Di Menna L, Riozzi B, Cannella M, Motolese M, Vetere G, Catania MV, Battaglia G, Nicoletti F, Nisticò R, Bruno V (2014) Changes in mGlu5 receptor-dependent synaptic plasticity and coupling to homer proteins in the hippocampus of Ube3A hemizygous mice modeling Angelman syndrome. J Neurosci 34:4558-4566.

Pirone L, Xolalpa W, Sigurðsson JO, Ramirez J, Pérez C, González M, de Sabando AR, Elortza F, Rodriguez MS, Mayor U, Olsen JV, Barrio R, Sutherland JD (2017) A comprehensive platform for the analysis of ubiquitin-like protein modifications using in vivo biotinylation. Sci Rep 7:40756.

Plant LD, Dowdell EJ, Dementieva IS, Marks JD, Goldstein SAN (2011) SUMO modification of cell surface Kv2.1 potassium channels regulates the activity of rat hippocampal neurons. J Gen Physiol 137:441-454.

Plant LD, Marks JD, Goldstein SA (2016) SUMOylation of NaV1.2 channels mediates the early response to acute hypoxia in central neurons. Elife 5:e20054.

Powell CM, Schoch S, Monteggia L, Barrot M, Matos MF, Feldmann N, Südhof TC, Nestler EJ (2004) The presynaptic active zone protein RIM1alpha is critical for normal learning and memory. Neuron 42:143-153.

Prieto M, Folci A, Martin S (2020) Post-translational modifications of the Fragile $X$ Mental Retardation Protein in neuronal function and dysfunction. Mol Psychiatry 25:1688-1703.

Psakhye I, Jentsch S (2012) Protein group modification and synergy in the SUMO pathway as exemplified in DNA repair. Cell 151:807820.

Puffenberger EG, Jinks RN, Wang H, Xin B, Fiorentini C, Sherman EA, Degrazio D, Shaw C, Sougnez C, Cibulskis K, Gabriel S, Kelley RI, Morton DH, Strauss KA (2012) A homozygous missense mutation in HERC2 associated with global developmental delay and autism spectrum disorder. Hum Mutat 33:1639-1646.

Qi Y, Wang J, Bomben VC, Li D-P, Chen S-R, Sun H, Xi Y, Reed JG, Cheng J, Pan H-L, Noebels JL, Yeh ETH (2014) HyperSUMOylation of the Kv7 potassium channel diminishes the M-current leading to seizures and sudden death. Neuron 83:1159-1171.

Quartier A, Poquet H, Gilbert-Dussardier B, Rossi M, Casteleyn AS, Portes Vd, Feger C, Nourisson E, Kuentz P, Redin C, Thevenon J, Mosca-Boidron AL, Callier P, Muller J, Lesca G, Huet F, Geoffroy V, El Chehadeh S, Jung M, Trojak B, et al. (2017) Intragenic FMR1 disease-causing variants: a significant mutational mechanism leading to Fragile-X syndrome. Eur J Hum Genet 25:423-431.

Ran M, Chen H, Liang B, Liao W, Jiang J, Huang J, Ning C, Zang N, Zhou B, Liao Y, Liu H, Qin F, Yang Q, Li J, Ho W, Liang H, Ye L (2018) Alcohol-induced autophagy via upregulation of PIASy promotes HCV replication in human hepatoma cells. Cell Death Dis 9:898.

Rezvani K, Teng Y, Shim D, De Biasi M (2007) Nicotine regulates multiple synaptic proteins by inhibiting proteasomal activity. J Neurosci 27:10508-10519.

Rezvani K, Baalman K, Teng Y, Mee MP, Dawson SP, Wang H, De Biasi M, Mayer RJ (2012) Proteasomal degradation of the metabotropic glutamate receptor $1 \alpha$ is mediated by Homer-3 via the proteasomal S8 ATPase: signal transduction and synaptic transmission. J Neurochem 122:24-37.

Rizo J, Xu J (2015) The synaptic vesicle release machinery. Annu Rev Biophys 44:339-367.

Rocca DL, Wilkinson KA, Henley JM (2017) SUMOylation of FOXP1 regulates transcriptional repression via CtBP1 to drive dendritic morphogenesis. Sci Rep 7:877.

Ropers HH, Hamel BCJ (2005) X-linked mental retardation. Nat Rev Genet 6:46-57. 
Saliba RS, Michels G, Jacob TC, Pangalos MN, Moss SJ (2007) Activity-dependent ubiquitination of $\mathrm{GABA}_{\mathrm{A}}$ receptors regulates their accumulation at synaptic sites. J Neurosci 27:13341-13351.

Saliba RS, Pangalos M, Moss SJ (2008) The ubiquitin-like protein Plic-1 enhances the membrane insertion of GABA A receptors by increasing their stability within the endoplasmic reticulum. J Biol Chem 283:18538-18544.

Salinas GD, Blair LAC, Needleman LA, Gonzales JD, Chen Y, Li M, Singer JD, Marshall J (2006) Actinfilin is a Cul3 substrate adaptor, linking GluR6 kainate receptor subunits to the ubiquitin-proteasome pathway. J Biol Chem 281:40164-40173.

Santiago-Sim T, Burrage LC, Ebstein F, Tokita MJ, Miller M, Bi W, Braxton AA, Rosenfeld JA, Shahrour M, Lehmann A, Cogné B, Küry S, Besnard T, Isidor B, Bézieau S, Hazart I, Nagakura $H$, Immken LL, Littlejohn RO, Roeder E, Kara B, et al. (2017) Biallelic variants in OTUD6B cause an intellectual disability syndrome associated with seizures and dysmorphic features. Am J Hum Genet 100:676-688.

Saraceno GE, Castilla R, Barreto GE, Gonzalez J, Kölliker-Frers RA, Capani F (2012) Hippocampal Dendritic Spines Modifications Induced by Perinatal Asphyxia. Neural Plast 2012:1-10.

Saran NG, Pletcher MT, Natale JE, Cheng Y, Reeves RH (2003) Global disruption of the cerebellar transcriptome in a Down syndrome mouse model. Hum Mol Genet 12:2013-2019.

Schorova L, Martin S (2016) Sumoylation in synaptic function and dysfunction. Front Synaptic Neurosci 8:1-24.

Schorova L, Pronot M, Poupon G, Prieto M, Folci A, Khayachi A, Brau F, Cassé F, Gwizdek C, Martin S (2019) The synaptic balance between sumoylation and desumoylation is maintained by the activation of metabotropic mGlu5 receptors. Cell Mol Life Sci 76:3019-3031.

Schwarz LA, Hall BJ, Patrick GN (2010) Activity-dependent ubiquitination of GluA1 mediates a distinct AMPA receptor endocytosis and sorting pathway. J Neurosci 30:16718-16729.

Scudder SL, Goo MS, Cartier AE, Molteni A, Schwarz LA, Wright R, Patrick GN (2014) Synaptic strength is bidirectionally controlled by opposing activity-dependent regulation of nedd4-1 and USP8. J Neurosci 34:16637-16649.

Scudder SL, Patrick GN (2015) Synaptic structure and function are altered by the neddylation inhibitor MLN4924. Mol Cell Neurosci 65:52-57.

Seebahn A, Rose M, Enz R (2008) RanBPM is expressed in synaptic layers of the mammalian retina and binds to metabotropic glutamate receptors. FEBS Lett 582:2453-2457.

Shalizi A, Gaudillière B, Yuan Z, Stegmüller J, Shirogane T, Ge Q, Tan Y, Schulman B, Harper JW, Bonni A (2006) A calcium-regulated MEF2 sumoylation switch controls postsynaptic differentiation. Science 311:1012-1017.

Shalizi A, Bilimoria PM, Stegmüller J, Gaudillière B, Yang Y, Shuai K, Bonni A (2007) PIASx is a MEF2 SUMO Elll ligase that promotes postsynaptic dendritic morphogenesis. J Neurosci 27:1003710046.

Sharma M, Li X, Wang Y, Zarnegar M, Huang C-Y, Palvimo JJ, Lim B, Sun Z (2003) hZimp10 is an androgen receptor co-activator and forms a complex with SUMO-1 at replication foci. EMBO J 22:6101-6114.

Sheng M, Hoogenraad CC (2007) The postsynaptic architecture of excitatory synapses: a more quantitative view. Annu Rev Biochem 76:823-847.

Sheng M, Kim E (2011) The postsynaptic organization of synapses. Cold Spring Harb Perspect Biol 3:a005678.

Shepherd JD, Rumbaugh G, Wu J, Chowdhury S, Plath N, Kuhl D, Huganir RL, Worley PF (2006) Arc/Arg3.1 mediates homeostatic synaptic scaling of AMPA receptors. Neuron 52:475-484.

Sitzmann AF, Hagelstrom RT, Tassone F, Hagerman RJ, Butler MG (2018) Rare FMR1 gene mutations causing fragile $X$ syndrome: a review. Am J Med Genet A 176:11-18.

Speese SD, Trotta N, Rodesch CK, Aravamudan B, Broadie K (2003) The ubiquitin proteasome system acutely regulates presynaptic protein turnover and synaptic efficacy. Curr Biol 13:899-910.
Steffan JS, Agrawal N, Pallos J, Rockabrand E, Trotman LC, Slepko $\mathrm{N}$, Illes K, Lukacsovich T, Zhu Y-Z, Cattaneo E, Pandolfi PP, Thompson LM, Marsh JL (2004) SUMO modification of Huntingtin and Huntington's disease pathology. Science 304:100-104.

Südhof TC (2004) The synaptic vesicle cycle. Annu Rev Neurosci 27:509-547.

Suizu F, Hiramuki Y, Okumura F, Matsuda M, Okumura AJ, Hirata N, Narita M, Kohno T, Yokota J, Bohgaki M, Obuse C, Hatakeyama S, Obata T, Noguchi M (2009) The EIII ligase TTC3 facilitates ubiquitination and degradation of phosphorylated Akt. Dev Cell 17:800810.

Sun J, Liu Y, Moreno S, Baudry M, Bi X (2015a) Imbalanced mechanistic target of rapamycin $\mathrm{C} 1$ and $\mathrm{C} 2$ activity in the cerebellum of Angelman syndrome mice impairs motor function. J Neurosci 35:4706-4718.

Sun J, Zhu G, Liu Y, Standley S, Ji A, Tunuguntla R, Wang Y, Claus C, Luo Y, Baudry M, Bi X (2015b) UBE3A regulates synaptic plasticity and learning and memory by controlling SK2 channel endocytosis. Cell Rep 12:449-461.

Tacer KF, Potts PR (2017) Cellular and disease functions of the Prader-Willi syndrome gene MAGEL2. Biochem J 474:2177-2190.

Tada H, Okano HJ, Takagi H, Shibata S, Yao I, Matsumoto M, Saiga T, Nakayama KI, Kashima H, Takahashi T, Setou M, Okano H (2010) Fbxo45, a novel ubiquitin ligase, regulates synaptic activity. J Biol Chem 285:3840-3849.

Tai DJC, Liu YC, Hsu WL, Ma YL, Cheng SJ, Liu SY, Lee EHY (2016) MeCP2 SUMOylation rescues Mecp2-mutant-induced behavioural deficits in a mouse model of Rett syndrome. Nat Commun 7:10552.

Takagi H, Setou M, Ito S, Yao I (2012) SCRAPPER regulates the thresholds of long-term potentiation/depression, the bidirectional synaptic plasticity in hippocampal CA3-CA1 synapses. Neural Plast 2012:352829.

Takahashi M, Itakura M, Kataoka M (2003) New aspects of neurotransmitter release and exocytosis: regulation of neurotransmitter release by phosphorylation. J Pharmacol Sci 93:41-45.

Tammsalu T, Matic I, Jaffray EG, Ibrahim AFM, Tatham MH, Hay RT (2014) Proteome-wide identification of SUMO2 modification sites. Sci Signal 7:rs2.

Tammsalu T, Matic I, Jaffray EG, Ibrahim AFM, Tatham MH, Hay RT (2015) Proteome-wide identification of SUMO modification sites by mass spectrometry. Nat Protoc 10:1374-1388.

Tang LTH, Craig TJ, Henley JM (2015) SUMOylation of synapsin la maintains synaptic vesicle availability and is reduced in an autism mutation. Nat Commun 6:7728.

Tang Z, Far O, El Betz H, Scheschonka A (2005) Pias1 interaction and sumoylation of metabotropic glutamate receptor 8 . J Biol Chem 280:38153-38159.

Taylor CP, Burke SP, Weber ML (1995) Hippocampal slices: glutamate overflow and cellular damage from ischemia are reduced by sodium-channel blockade. J Neurosci Methods 59:121-128.

Tentler D, Johannesson T, Johansson M, Råstam M, Gillberg C, Orsmark C, Carlsson B, Wahlström J, Dahl N (2003) A candidate region for Asperger syndrome defined by two 17p breakpoints. Eur J Hum Genet 11:189-195.

Tirard M, Hsiao $\mathrm{H}-\mathrm{H}$, Nikolov M, Urlaub $\mathrm{H}$, Melchior F, Brose $\mathrm{N}$ (2012) In vivo localization and identification of SUMOylated proteins in the brain of His6-HA-SUMO1 knock-in mice. Proc Natl Acad Sci USA 109:21122-21127.

Tomoda T, Yang K, Sawa A (2020) Neuronal autophagy in synaptic functions and psychiatric disorders. Biol Psychiatry 87:787-796.

Tønne E, Holdhus R, Stansberg C, Stray-Pedersen A, Petersen K, Brunner HG, Gilissen C, Hoischen A, Prescott T, Steen VM, Fiskerstrand T (2015) Syndromic X-linked intellectual disability segregating with a missense variant in RLIM. Eur J Hum Genet 23:1652-1656.

Tramutola A, Di Domenico F, Barone E, Arena A, Giorgi A, di Francesco L, Schininà ME, Coccia R, Head E, Butterfield DA, Perluigi M (2017) Polyubiquitinylation profile in Down syndrome 
brain before and after the development of Alzheimer neuropathology. Antioxid Redox Signal 26:280-298.

Tyagarajan SK, Ghosh H, Yévenes GE, Nikonenko I, Ebeling C, Schwerdel C, Sidler C, Zeilhofer HU, Gerrits B, Muller D, Fritschy JM (2011) Regulation of GABAergic synapse formation and plasticity by GSK3beta-dependent phosphorylation of gephyrin. Proc Natl Acad Sci USA 108:379-384.

Tyagarajan SK, Fritschy J-M (2014) Gephyrin: a master regulator of neuronal function? Nat Rev Neurosci 15:141-156.

Upadhyay A, Joshi V, Amanullah A, Mishra R, Arora N, Prasad A, Mishra A (2017) Elll ubiquitin ligases neurobiological mechanisms: development to degeneration. Front Mol Neurosci 10:1-21.

Usui N, Co M, Harper M, Rieger MA, Dougherty JD, Konopka G (2017) Sumoylation of FOXP2 regulates motor function and vocal communication through Purkinje cell development. Biol Psychiatry 81:220-230.

Valnegri P, Huang J, Yamada T, Yang Y, Mejia LA, Cho HY, Oldenborg A, Bonni A (2017) RNF8/UBC13 ubiquitin signaling suppresses synapse formation in the mammalian brain. Nat Commun 8:1271.

van Roessel P, Elliott DA, Robinson IM, Prokop A, Brand AH (2004) Independent regulation of synaptic size and activity by the anaphase-promoting complex. Cell 119:707-718.

Van Spronsen M, Hoogenraad CC (2010) Synapse pathology in psychiatric and neurologic disease. Curr Neurol Neurosci Rep 10:207-214.

van Woerden GM, Harris KD, Hojjati MR, Gustin RM, Qiu S, de Avila Freire R, Jiang Y, Elgersma Y, Weeber EJ (2007) Rescue of neurological deficits in a mouse model for Angelman syndrome by reduction of alphaCaMKII inhibitory phosphorylation. Nat Neurosci 10:280-282.

Verpelli C, Sala C (2012) Molecular and synaptic defects in intellectual disability syndromes. Curr Opin Neurobiol 22:530-536.

Vicidomini C, Ponzoni L, Lim D, Schmeisser MJ, Reim D, Morello N, Orellana D, Tozzi A, Durante V, Scalmani P, Mantegazza M, Genazzani AA, Giustetto M, Sala M, Calabresi P, Boeckers TM, Sala C, Verpelli C (2017) Pharmacological enhancement of mGlu5 receptors rescues behavioral deficits in SHANK3 knock-out mice. Mol Psychiatry 22:689-702.

Vilardell M, Rasche A, Thormann A, Maschke-Dutz E, Pérez-Jurado LA, Lehrach H, Herwig R (2011) Meta-analysis of heterogeneous Down Syndrome data reveals consistent genome-wide dosage effects related to neurological processes. BMC Genomics 12:229.

Vissers LELM, Gilissen C, Veltman JA (2016) Genetic studies in intellectual disability and related disorders. Nat Rev Genet 17:9-18.

Vogl AM, Brockmann MM, Giusti SA, MacCarrone G, Vercelli CA, Bauder CA, Richter JS, Roselli F, Hafner AS, Dedic N, Wotjak CT, Vogt-Weisenhorn DM, Choquet D, Turck CW, Stein V, Deussing JM, Refojo D (2015) Neddylation inhibition impairs spine development, destabilizes synapses and deteriorates cognition. Nat Neurosci 18:239-251.

Vogl AM, Phu L, Becerra R, Giusti SA, Verschueren E, Hinkle TB, Bordenave MD, Adrian M, Heidersbach A, Yankilevich P, Stefani FD, Wurst W, Hoogenraad CC, Kirkpatrick DS, Refojo D, Sheng M (2020) Global site-specific neddylation profiling reveals that NEDDylated cofilin regulates actin dynamics. Nat Struct Mol Biol 27:210-220

Waites CL, Leal-Ortiz SA, Okerlund N, Dalke H, Fejtova A, Altrock WD, Gundelfinger ED, Garner CC (2013) Bassoon and Piccolo maintain synapse integrity by regulating protein ubiquitination and degradation. EMBO J 32:954-969.

Wallace ML, Burette AC, Weinberg RJ, Philpot BD (2012) Maternal loss of Ube3a produces an excitatory/inhibitory imbalance through neuron type-specific synaptic defects. Neuron 74:793-800.

Walters BJ, Hallengren JJ, Theile CS, Ploegh HL, Wilson SM, Dobrunz LE (2014) A catalytic independent function of the deubiquitinating enzyme USP14 regulates hippocampal synaptic shortterm plasticity and vesicle number. J Physiol 592:571-586.

Wang HL, Chang NC, Weng YH, Yeh TH (2013) XLID CUL4B mutants are defective in promoting TSC2 degradation and positively regulating mTOR signaling in neocortical neurons. Biochim Biophys Acta 1832:585-593.

Wang L, Rodriguiz R, Wetsel W, Sheng H, Zhao S, Liu X, Paschen W, Yang W (2014) Neuron-specific Sumo1-3 knockdown in mice impairs episodic and fear memories. J Psychiatry Neurosci 39:259266.

Wang Q, Liu L, Pei L, Ju W, Ahmadian G, Lu J, Wang Y, Liu F, Wang YT (2003) Control of synaptic strength, a novel function of Akt. Neuron 38:915-928.

Wang J, Lou SS, Wang T, Wu RJ, Li G, Zhao M, Lu B, Li YY, Zhang J, Cheng X, Shen Y, Wang X, Zhu ZC, Li MJ, Takumi T, Yang H, Yu X, Liao L, Xiong ZQ (2019a) UBE3A-mediated PTPA ubiquitination and degradation regulate PP2A activity and dendritic spine morphology. Proc Natl Acad Sci USA 116:12500-12505.

Wang T, Wang J, Wang J, Mao L, Tang B, Vanderklish PW, Liao X, Xiong ZQ, Liao L (2019b) HAP1 is an in vivo UBE3A target that augments autophagy in a mouse model of Angelman syndrome. Neurobiol Dis 132:104585.

Watanabe M, Takahashi K, Tomizawa K, Mizusawa H, Takahashi H (2008) Developmental regulation of Ubc9 in the rat nervous system. Acta Biochim Pol 55:681-686.

Waung MW, Pfeiffer BE, Nosyreva ED, Ronesi JA, Huber KM (2008) Rapid translation of Arc/Arg3.1 selectively mediates mGluR-dependent LTD through persistent increases in AMPAR endocytosis rate. Neuron 59:84-97.

Weber ML, Taylor CP (1994) Damage from oxygen and glucose deprivation in hippocampal slices is prevented by tetrodotoxin, lidocaine and phenytoin without blockade of action potentials. Brain Res 664:167-177.

Weeber EJ, Jiang Y-H, Elgersma Y, Varga AW, Carrasquillo Y, Brown SE, Christian JM, Mirnikjoo B, Silva A, Beaudet AL, Sweatt JD (2003) Derangements of hippocampal calcium/calmodulin-dependent protein kinase II in a mouse model for Angelman mental retardation syndrome. J Neurosci 23:2634-2644.

Welch MA, Forster LA, Atlas SI, Baro DJ (2019) SUMOylating two distinct sites on the A-type potassium channel, Kv4.2, increases surface expression and decreases current amplitude. Front Mol Neurosci 12:144.

Widagdo J, Chai YJ, Ridder MC, Chau YQ, Johnson RC, Sah P, Huganir RL, Anggono V (2015) Activity-dependent ubiquitination of GluA1 and GluA2 regulates AMPA receptor intracellular sorting and degradation. Cell Rep 10:783-795.

Wilkinson KA, Henley JM (2011) Analysis of metabotropic glutamate receptor 7 as a potential substrate for SUMOylation. Neurosci Lett 491:181-186.

Wilkinson KA, Martin S, Tyagarajan SK, Arancio O, Craig TJ, Guo C, Fraser PE, Goldstein SAN, Henley JM (2017) Commentary: analysis of SUMO1-conjugation at synapses. Front Cell Neurosci 11:2016-2018.

Willeumier K, Pulst SM, Schweizer FE (2006) Proteasome inhibition triggers activity-dependent increase in the size of the recycling vesicle pool in cultured hippocampal neurons. I Neurosci 26:11333-11341.

Wilson SM, Bhattacharyya B, Rachel RA, Coppola V, Tessarollo L, Householder DB, Fletcher CF, Miller RJ, Copeland NG, Jenkins NA (2002) Synaptic defects in ataxia mice result from a mutation in Usp14, encoding a ubiquitin-specific protease. Nat Genet 32:420425.

Yang CY, Yu TH, Wen WL, Ling P, Hsu KS (2019) Conditional deletion of CC2D1A reduces hippocampal synaptic plasticity and impairs cognitive function through Rac1 hyperactivation. J Neurosci 39:4959-4975.

Yao I, Takagi H, Ageta H, Kahyo T, Sato S, Hatanaka K, Fukuda Y, Chiba T, Morone N, Yuasa S, Inokuchi K, Ohtsuka T, MacGregor GR, Tanaka K, Setou M (2007) SCRAPPER-dependent ubiquitination of active zone protein RIM1 regulates synaptic vesicle release. Cell 130:943-957.

Yao I, Takao K, Miyakawa T, Ito S, Setou M (2011) Synaptic EllI ligase SCRAPPER in contextual fear conditioning: extensive 
behavioral phenotyping of scrapper heterozygote and overexpressing mutant mice. PLoS One 6:e17317.

Yashiro K, Riday TT, Condon KH, Roberts AC, Bernardo DR, Prakash R, Weinberg RJ, Ehlers MD, Philpot BD (2009) Ube3a is required for experience-dependent maturation of the neocortex. Nat Neurosci 12:777-783.

Yeh SH, Mao SC, Lin HC, Gean PW (2006) Synaptic expression of glutamate receptor after encoding of fear memory in the rat amygdala. Mol Pharmacol 69:299-308.

Yoo DY, Won Kim D, Kwon HJ, Jung HY, Nam SM, Kim JW, Chung JY, Won MH, Yoon YS, Choi SY, Hwang IK (2017) Chronic administration of SUMO-1 has negative effects on novel object recognition memory as well as cell proliferation and neuroblast differentiation in the mouse dentate gyrus. Mol Med Rep 16:34273432.

Zacchi P, Antonelli R, Cherubini E (2014) Gephyrin phosphorylation in the functional organization and plasticity of GABAergic synapses. Front Cell Neurosci 8:103.

Zeng F, Ma X, Zhu L, Xu Q, Zeng Y, Gao Y, Li G, Guo T, Zhang H, Tang X, Wang Z, Ye Z, Zheng L, Zhang H, Zheng Q, Li K, Lu J, Qi $X$, Luo H, Zhang X, et al. (2019) The deubiquitinase USP6 affects memory and synaptic plasticity through modulating NMDA receptor stability. PLOS Biol 17:e3000525.

Zhang H, Kang E, Wang Y, Yang C, Yu H, Wang Q, Chen Z, Zhang C, Christian KM, Song H, Ming G, Xu Z (2016) Brain-specific Crmp2 deletion leads to neuronal development deficits and behavioural impairments in mice. Nat Commun 7:11773.

Zhang J, Gambin T, Yuan B, Szafranski P, Rosenfeld JA, Balwi MA, Alswaid A, Al-Gazali L, Shamsi AMA, Komara M, Ali BR, Roeder E, McAuley L, Roy DS, Manchester DK, Magoulas P, King LE, Hannig V, Bonneau D, Denommé-Pichon AS, et al. (2017) Haploinsufficiency of the Elll ubiquitin-protein ligase gene TRIP12 causes intellectual disability with or without autism spectrum disorders, speech delay, and dysmorphic features. Hum Genet 136:377-386.

Zhang J, Zhao B, Zhu X, Li J, Wu F, Li S, Gong X, Cha C, Guo G (2018) Phosphorylation and SUMOylation of CRMP2 regulate the formation and maturation of dendritic spines. Brain Res Bull 139:21-30.

Zhang Y, Li Z, Gu J, Zhang Y, Wang W, Shen H, Chen G, Wang X (2015) Plic-1, a new target in repressing epileptic seizure by regulation of GABAAR function in patients and a rat model of epilepsy. Clin Sci 129:1207-1223.

Zhao M, Raingo J, Chen ZJ, Kavalali ET (2011) Cc2d1a, a C2 domain containing protein linked to nonsyndromic mental retardation, controls functional maturation of central synapses. J Neurophysiol 105:1506-1515.

Zou Y, Liu Q, Chen B, Zhang X, Guo C, Zhou H, Li J, Gao G, Guo Y, Yan C, Wei J, Shao C, Gong Y (2007) Mutation in CUL4B, which encodes a member of cullin-RING ubiquitin ligase complex, causes X-linked mental retardation. Am J Hum Genet 80:561566. 